\title{
Microcircuits Mediating Feedforward and Feedback Synaptic Inhibition in the Piriform Cortex
}

\author{
Norimitsu Suzuki and John M. Bekkers \\ Department of Neuroscience, The John Curtin School of Medical Research, The Australian National University, Canberra, Australian Capital Territory 0200, \\ Australia
}

Local inhibition by GABA-releasing neurons is important for the operation of sensory cortices, but the details of these inhibitory circuits remain unclear. We addressed this question in the olfactory system by making targeted recordings from identified classes of inhibitory and glutamatergic neurons in the piriform cortex (PC) of mice. First, we looked for feedforward synaptic inhibition provided by interneurons located in the outermost layer of the PC, layer Ia, which is the unique recipient of afferent fibers from the olfactory bulb. We found two types of feedforward inhibition: a fast-rising, spatially restricted kind that was generated by horizontal cells, and a slow-rising, more diffuse kind generated by neurogliaform cells. Both cell types targeted the distal apical dendrites of layer II principal neurons. Next, we studied feedback synaptic inhibition in isolation by making a tissue cut across layer I to selectively remove feedforward inhibitory connections. We identified a powerful type of feedback inhibition of layer II neurons, mostly generated by soma-targeting fast-spiking multipolar cells in layer III, which in turn were driven by feedforward excitation from layer II semilunar cells. Dynamic clamp simulation of feedback inhibition revealed differential effects of this inhibition on the two main types of layer II principal neurons. Thus, our results articulate the connectivity and functions of two important classes of inhibitory microcircuits in the PC. Feedforward and feedback inhibition generated by these circuits is likely to be required for the operation of this sensory paleocortex during the processing of olfactory information.

\section{Introduction}

Synaptic inhibition is critical for the ability of cortical circuits to process information (Gabernet et al., 2005; Yoshimura and Callaway, 2005; Silver, 2010; Isaacson and Scanziani, 2011). Precisely how inhibition achieves this task, however, has been difficult to establish, in part because of the great diversity of cortical interneurons (Markram et al., 2004; Ascoli et al., 2008; Moore et al., 2010). One approach to this problem has been to identify inhibitory microcircuits - canonical "circuit motifs"- that might constitute the functional building blocks of synaptic inhibition in the cortex (DeFelipe, 2002; Isaacson and Scanziani, 2011). In this paper we use this approach to characterize feedforward and feedback inhibitory microcircuits in the primary olfactory (piriform) cortex of mice.

The piriform cortex (PC) is a trilaminar paleocortex located in the ventral forebrain, where it is the first cortical recipient of olfactory information from the olfactory bulb (Neville and Haberly, 2004). The PC is thought to perform a high-level synthetic role by recognizing and remembering odors (Wilson and Steven-

\footnotetext{
Received Aug. 9, 2011; revised 0ct. 26, 2011; accepted Nov. 20, 2011.

Author contributions: N.S. and J.M.B. designed research; N.S. performed research; N.S. and J.M.B. analyzed data; N.S. and J.M.B. wrote the paper.

This work was supported by Project Grants 471413 and 585462 from the National Health and Medical Research Council of Australia to J.M.B. We thank Yuchio Yanagawa for providing the GAD67-GFP $(\Delta$ neo $)$ mice.

Correspondence should be addressed to John M. Bekkers, Department of Neuroscience, John Curtin School of Medical Research, Building 131, The Australian National University, Canberra, ACT 0200, Australia. E-mail: John.Bekkers@anu.edu.au.

DOI:10.1523/JNEUROSCI.4112-11.2012

Copyright $\odot 2012$ the authors $\quad 0270-6474 / 12 / 320919-13 \$ 15.00 / 0$
}

son, 2006). Because of its comparatively simple anatomy, together with the fact that its afferent inputs (i.e., the outputs of the bulb) are increasingly well understood, the PC has attracted attention as a model system for the study of cortical sensory processing (Neville and Haberly, 2004; Franks and Isaacson, 2005, 2006; Suzuki and Bekkers, 2006, 2011; Barnes et al., 2008; Luna and Schoppa, 2008; Bathellier et al., 2009; Johenning et al., 2009; Poo and Isaacson, 2009; Stettler and Axel, 2009; Stokes and Isaacson, 2010; Wilson, 2010; Davison and Ehlers, 2011; Franks et al., 2011; Poo and Isaacson, 2011; Wiegand et al., 2011). In particular, synaptic inhibition in the PC is of interest because of its likely relevance to olfactory coding and oscillations (Wilson and Bower, 1992; Kay et al., 2009; Poo and Isaacson, 2009, 2011; Kay and Beshel, 2010; Zhan and Luo, 2010; Manabe et al., 2011; Zelano et al., 2011).

We have recently completed a rigorous classification of the main types of inhibitory interneurons in the PC (Suzuki and Bekkers, 2010a,b). Here, we take the next step by studying some of the basic microcircuits in which these different classes of interneurons are embedded. By taking advantage of the simple laminar structure of the PC, as well as our knowledge of interneuron types, we focus on two ubiquitous circuit motifs, feedforward and feedback inhibition. We show that feedforward inhibition occurs in two variants, provided by neurogliaform (NG) and horizontal (HZ) cells located in the superficial input layer of the PC. Feedback inhibition, by contrast, is mostly provided by fast-spiking multipolar cells located in deeper layers. These cells, driven mainly by layer II semilunar neurons, project very densely to the somata of principal cells in the PC, providing global inhibition of 
principal cell output. Hence, our findings articulate some fundamental circuit motifs in the PC and suggest mechanisms that could underlie cortical oscillations and sensory processing in this cortical region.

\section{Materials and Methods}

Slice preparation. All experiments used acute brain slices (300 $\mu \mathrm{m}$ thick) prepared from the anterior PC of heterozygous GAD67-GFP $(\Delta$ neo) mice $(18-25 \mathrm{~d}$ old, of either sex) in which green fluorescent protein (GFP) is specifically expressed in neurons containing GABA (Tamamaki et al., 2003). These animals, made on a C57BL/6J background, have normal behavior and neuroanatomy (Kerlin et al., 2010; Suzuki and Bekkers, 2010a; Zhan and Luo, 2010), and GFP ${ }^{+}$cells in these mice have the electrical and morphological features of normal GABAergic interneurons (Suzuki and Bekkers, 2010b). Use of GAD67-GFP ( $\Delta$ neo) mice greatly facilitated targeted recordings from inhibitory interneurons. Standard methods of slice preparation were used (Suzuki and Bekkers, $2006,2010 b)$. Briefly, mice were deeply anesthetized with isoflurane ( $2 \%$ in oxygen) then rapidly decapitated using procedures approved by the Animal Experimentation Ethics Committee of the Australian National University. Coronal or parasagittal slices containing the lateral olfactory tract (LOT) were prepared using a vibrating slicer (Campden Instruments) under ice-cold cutting solution comprising (in $\mathrm{mM}$ ) $125 \mathrm{NaCl}, 3$ $\mathrm{KCl}, 0.5 \mathrm{CaCl}_{2}, 6 \mathrm{MgCl}_{2}, 25 \mathrm{NaHCO}_{3}, 1.25 \mathrm{NaH}_{2} \mathrm{PO}_{4}$, and 10 glucose (osmolarity $305 \mathrm{mOsm} / \mathrm{kg}$ ), bubbled with $5 \% \mathrm{CO}_{2} / 95 \% \mathrm{O}_{2}$ (carbogen). The slices were incubated for $1 \mathrm{~h}$ at $35^{\circ} \mathrm{C}$ in a holding chamber containing carbogen-bubbled artificial CSF (ACSF; composition below), then were held at room temperature until required.

Electrophysiology. Standard techniques were used to make visualized whole-cell patch-clamp recordings from $\mathrm{GFP}^{+}$neurons in all layers or $\mathrm{GFP}^{-}$glutamatergic principal neurons in layer II of the PC. The different classes of GABAergic interneurons were identified by their characteristic electrical properties, morphologies, and laminar location, as previously described (Suzuki and Bekkers, 2010a,b). Note that, in the current paper, the fast-spiking multipolar cells we recorded from were restricted to those in layer III. Layer II principal cells were identified as being either semilunar (SL) or superficial pyramidal (SP) cells based on their soma location (layer IIa and layer IIb, respectively) and their dendritic morphology (without and with basal dendrites, respectively; Suzuki and Bekkers, 2006, 2011). In experiments using a potassium-based internal solution (below), this identification was confirmed from their characteristic firing and passive electrical properties (Suzuki and Bekkers, 2006).

Slices were continuously superfused $(2-3 \mathrm{ml} / \mathrm{min})$ with ACSF comprising (in mM) $125 \mathrm{NaCl}, 3 \mathrm{KCl}, 2 \mathrm{CaCl}_{2}, 1 \mathrm{MgCl}_{2}, 25 \mathrm{NaHCO}_{3}, 1.25$ $\mathrm{NaH}_{2} \mathrm{PO}_{4}$, and 25 glucose ( $310 \mathrm{mOsm} / \mathrm{kg}$ ), bubbled with $5 \% \mathrm{CO}_{2} / 95 \%$ $\mathrm{O}_{2}$ (carbogen), and maintained at $33-35^{\circ} \mathrm{C}$. For current-clamp recordings, patch electrodes had resistances of 6-10 $\mathrm{M} \Omega$ when filled with internal solution containing (in mM) $135 \mathrm{KMeSO}_{4}, 7 \mathrm{NaCl}, 0.1$ EGTA, 2 $\mathrm{Na}_{2} \mathrm{ATP}, 2 \mathrm{MgCl}_{2}, 0.3 \mathrm{GTP}, 10$ HEPES at $\mathrm{pH}$ 7.2, supplemented with $0.2-0.4 \%$ biocytin $(295-300 \mathrm{mOsm} / \mathrm{kg})$. This solution had a Cl${ }^{-}$concentration of $11 \mathrm{~mm}$ and a measured junction potential of $-7 \mathrm{mV}$. For voltage-clamp recordings, $135 \mathrm{~mm}$ Cs methane sulfonate replaced the $\mathrm{KMeSO}_{4}$ and electrodes had resistances of 5-7 M $\Omega$. For the experiments in Figure $1 \mathrm{a}$ lower-chloride $\left(2 \mathrm{mM} \mathrm{Cl}^{-}\right)$internal solution was used, containing (in mM) $135 \mathrm{Cs}$ methane sulfonate, $1 \mathrm{NaCl}, 1 \mathrm{KCl}, 0.1$ EGTA, 2 MgATP, 0.3 GTP, 5 creatine phosphate (Na salt), 10 HEPES at pH 7.2 (295-300 mOsm/kg). For some voltage-clamp recordings (see Figs. 6, 7) the $\mathrm{KMeSO}_{4}$ current clamp internal solution was used, to which was added $100 \mu \mathrm{M}$ spermine. Gramicidin-perforated patch experiments used a high-chloride pipette solution containing (in mM) $140 \mathrm{KCl}, 10 \mathrm{HEPES}$ at $\mathrm{pH} 7.2$, to which was added gramicidin at $9 \mu \mathrm{g} / \mathrm{ml}$ (Gulledge and Stuart, 2003). With this solution, inadvertent rupture of the perforated patch was apparent as a large depolarizing shift in the chloride reversal potential. All voltages given in this paper are corrected for junction potentials. Unless stated otherwise, all compounds were obtained from Sigma-Aldrich.

Data were acquired using a Multiclamp 700A amplifier (Molecular Devices). For current-clamp recordings, the cell was allowed to remain at
A Stim

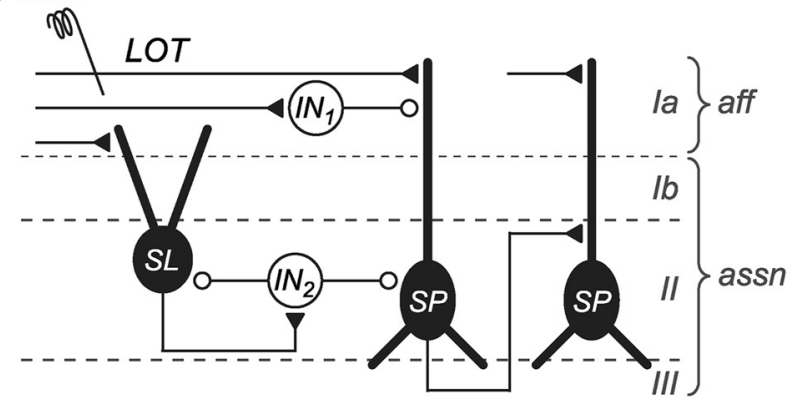

B

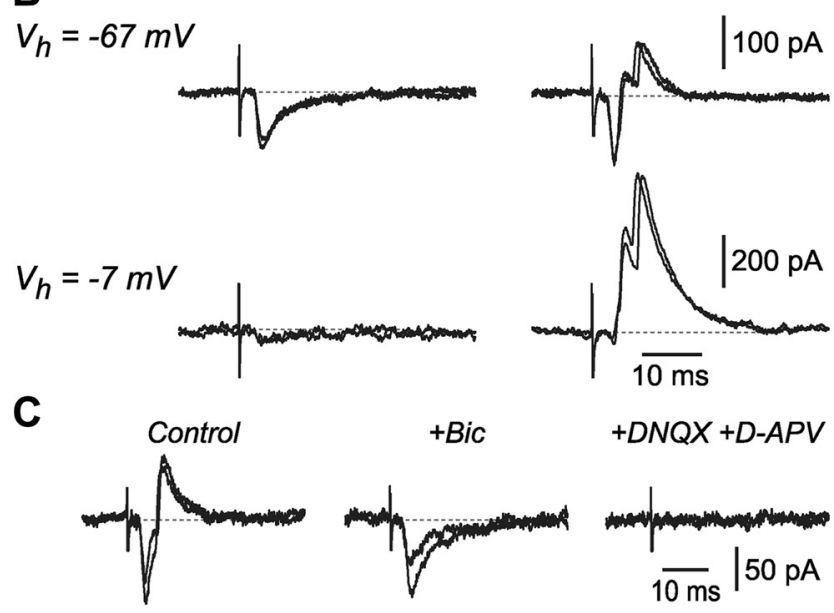

Figure 1. Stimulation of the LOT reveals polysynaptic inhibition in layer II principal cells. $\boldsymbol{A}$, Proposed circuit diagram to guide the experiments described in this paper. Feedforward inhibition is mediated by interneurons IN1 located in the afflayer (la), whereas feedback inhibition is mediated by interneurons IN2 located in one of the deeper assn layers (Ib, II, III). Two targets of synaptic inhibition are SL and SP glutamatergic neurons with their somata located in layer II. $B$, Postsynaptic currents recorded in an SL cell following weaker ( $15 \mu \mathrm{A}$, left) and stronger (50 $\mu \mathrm{A}$, right) stimulation of the $\mathrm{LOT}$, with the holding potential fixed at either $-67 \mathrm{mV}$ (top) or $-7 \mathrm{mV}$ (bottom). Each panel shows two superimposed traces. With weaker stimulation, an inward EPSC is apparent at $-67 \mathrm{mV}$; it reverses near $-7 \mathrm{mV}$. With stronger stimulation, an additional outward IPSC appears at longer latency; its amplitude is increased at $-7 \mathrm{mV}$. In this experiment the electrode solution contained low $\mathrm{Cl}^{-}(2 \mathrm{~mm})$. Calibration bars at right also apply to left-hand panels. Stimulus artifacts have been clipped. C, Synaptic currents measured in an SL cell in control solution (left), in $10 \mu \mathrm{m}$ bicuculline (middle), or in bicuculline plus $10 \mu \mathrm{m}$ DNQX and $25 \mu \mathrm{m} \mathrm{D}$-APV (right). Each panel shows two traces superimposed. Holding potential -67 $\mathrm{mV}$, stimulus strength $35 \mu \mathrm{A}$.

its resting membrane potential. Bridge balance and capacitance neutralization were carefully adjusted and checked for stability. For voltage-clamp recordings, series resistance was monitored for stability but series resistance compensation was not used. Voltage or current traces were filtered at $10 \mathrm{kHz}$ and digitized at 20 or $50 \mathrm{kHz}$ by an ITC-18 interface (Instrutech/HEKA) under the control of Axograph (Axograph Scientific).

The dynamic clamp was implemented with a custom procedure written in Igor Pro (WaveMetrics) using an XOP (external operation file) for the ITC-18 interface to enable high-speed performance (Bekkers, 2011). The inhibitory synaptic conductance was described by $g(t)=g_{0}\left(1-e^{-t / \tau_{1}}\right)^{2} e^{-t / \tau_{2}}$, where $g_{0}$ is a scale factor, and $\tau_{1}$ and $\tau_{2}$ are the time constants for the rising and falling phases, respectively. The time constants were estimated from fits of the above equation to averaged IPSCs from experiments as in Figure $8 \mathrm{~A}$, left (see below), yielding $\tau_{1}=0.8 \pm 0.2 \mathrm{~ms}, \tau_{2}=14.5 \pm 0.9 \mathrm{~ms}$ ( $n=6$ cell pairs $)$. Hence, the following values were used in the dynamic clamp: $\tau_{1}=0.8 \mathrm{~ms}, \tau_{2}=$ $15 \mathrm{~ms}$. The scale factor, $g_{0}$, was chosen to give the peak conductance stated in the Results. The reversal potential was set at $-85 \mathrm{mV}$, close to the average obtained from the gramicidin experiments (Results). 
A Far from LOT

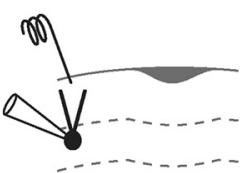

Near LOT

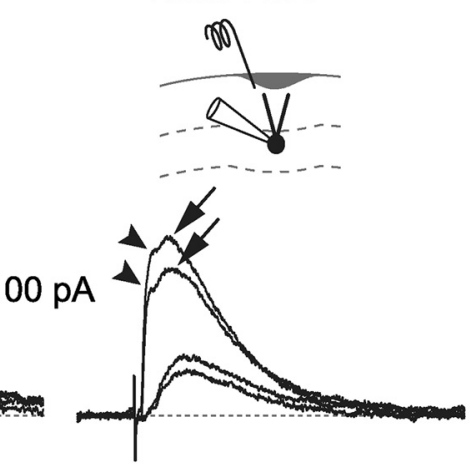

B

Near

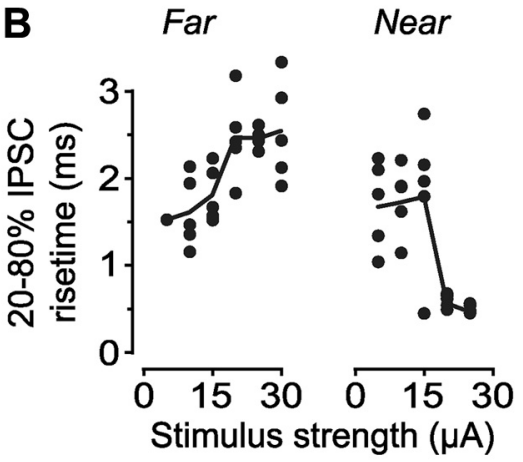

Figure 2. Two types of feedforward inhibition can be distinguished close to the LOT. A, Left, IPSCS recorded in an SL cell located far ( $>400 \mu \mathrm{m}$ ) from the LOT in a coronal slice (holding potential $+3 \mathrm{mV}$ ). The extracellular stimulating electrode was placed in superficial layer la directly above the SL cell soma. Two smaller traces (stimulus current $15 \mu \mathrm{A}$ ) and two larger traces (stimulus $20 \mu \mathrm{A}$ ) are superimposed. Stimulus artifacts have been clipped. Right, Similar recording made from an SL cell immediately below the $\mathrm{L} 0 \mathrm{~T}$. In this case, the weaker stimulus (15 $\mu \mathrm{A}$, two smaller traces) elicits a purely slow-rising IPSC, whereas the stronger stimulus (20 $\mu \mathrm{A}$, two larger traces) recruits a fast-rising IPSC (below arrowheads) upon which the slow-rising IPSC is superimposed (arrows). $\boldsymbol{B}$, Plots of $20-80 \%$ IPSC rise time versus stimulus strength for the Far cell in $\boldsymbol{A}$ (left) and the Near cell in $\boldsymbol{A}$ (right). For the Near cell, when a fast-rising IPSC component was apparent at stronger stimuli, the rise-time measurements defined the peak as occurring at the inflection immediately after the fast rise (arrowheads). Points show individual measurements at each stimulus strength; line indicates average.

Focal extracellular synaptic stimulation was done using a custom-built isolated stimulator that delivered a $100-\mu$ s-long constant current pulse with an adjustable amplitude. Single stimuli or trains of stimuli were applied at 10 or $15 \mathrm{~s}$ intervals. The stimulating electrode was constructed from a patch electrode (tip diameter $\sim 5 \mu \mathrm{m}$ ) filled with $1 \mathrm{M} \mathrm{NaCl}$ and coated with electrically conductive paint. The stimulus current was passed between the filling solution and a wire connected to the paint; hence, this functioned as a concentric bipolar stimulating electrode (Bekkers and Clements, 1999). The lateral olfactory tract was excited by placing the stimulating electrode at the LOT/layer Ia border or (Fig. $2 \mathrm{~A}$, left) at the upper margin of layer Ia. For experiments in which minimal stimulation was used, the stimulus strength was reduced until synaptic failures occurred on $20-50 \%$ of trials. Tissue cuts (see Fig. 4 ) were made by hand under a dissecting microscope. Care was taken to fully transect layer Ia but sometimes the cut extended into layer Ib; this did not affect the results.

In the gramicidin experiments GABA was applied using a Picospritzer (Parker Hannifin) via a puffer pipette near the cell soma (200 $\mu \mathrm{M}$ GABA in the puffer). The bath and puffer solutions also contained CGP 55845 $(5 \mu \mathrm{M})$ to block $\mathrm{GABA}_{\mathrm{B}}$ receptors. The access resistance was in the range $40-80 \mathrm{M} \Omega$. Bridge balance was carefully monitored and adjusted during the experiment. Recordings were made in current-clamp mode, and the membrane potential was varied using steady current injection. Experi- ments used SL and SP cells alternately to ensure that the recording conditions were identical.

At the conclusion of the recording, patch electrodes were carefully retracted while maintaining the seal. The slice was fixed for $1 \mathrm{~h}$ in $4 \%$ paraformaldehyde in PBS then stored in PBS at $4^{\circ} \mathrm{C}$ until processing. Neuronal morphology was revealed using an $\mathrm{ABC}$ kit (Vector Laboratories) and diaminobenzidine. Cell tracing was done manually using the Neurolucida tracing system (MBF Bioscience).

Analysis. All electrophysiological analysis was done using either Axograph or Igor Pro. Synaptic latencies were measured from the peak of the stimulus artifact to the foot of the postsynaptic current. Action potential (AP) latencies were measured from the artifact to the peak of the AP. Synaptic rise times were measured between $20 \%$ and $80 \%$ of the peak of the synaptic current, except for fast-rising currents like those in Figure $2 \mathrm{~A}$ (right), where the inflection at the end of the fast rise (Fig. $2 \mathrm{~A}$, arrowheads) was taken as the peak. Synaptic currents were converted to conductances using the measured reversal potentials for EPSCs and IPSCs (0 $\mathrm{mV}$ and $-67 \mathrm{mV}$, respectively, for our usual $11 \mathrm{mM} \mathrm{Cl}^{-}$internal solution, after correcting for the junction potential). EPSP half-width (see Fig. $9 B$ ) was the width of the EPSP measured at half its peak amplitude. The probability of firing an AP (see Figs. 5, 9D, 10C) was calculated as the fraction of 5 or 10 sequential episodes (all recorded at a fixed stimulus current) in which at least one synaptically evoked AP was elicited. All errors and error bars represent \pm SEM, with $n$ the number of cells. Unless stated otherwise, statistical comparisons used the unpaired two-tailed $t$ test.

\section{Results}

Stimulation of afferent inputs to the piriform cortex reveals delayed synaptic inhibition in layer II principal neurons

The piriform cortex is a highly laminated structure with a strict segregation of its excitatory inputs (Fig. $1 A$; Neville and Haberly, 2004). Afferent (aff) inputs from the olfactory bulb arrive via the LOT, forming excitatory synapses in layer Ia on the distal dendrites of two broad classes of layer II principal neurons, SL and SP cells. Associational (assn) inputs, many of which arise from principal neurons in the ipsi- and contralateral PC, are restricted to deeper layers (Ib, II, III). This circuit design immediately suggests the likely presence of two kinds of synaptic inhibition of principal neurons, i.e., feedforward inhibition, mediated by GABAergic neurons in the superficial aff layer (IN1, Fig. $1 A$ ), and feedback inhibition, mediated by neurons in deeper assn layers (IN2, Fig. 1 A; Satou et al., 1983; Haberly and Bower, 1984; Haberly et al., 1987; Tseng and Haberly, 1988; Wilson and Bower, 1992).

Weak electrical stimulation of the LOT elicited a pure EPSC in both SL and SP cells due to aff excitatory input (Fig. $1 \mathrm{~B}$, left; recording from SL cell). As expected for glutamatergic currents, this EPSC reversed near a holding potential of $0 \mathrm{mV}$ (Fig. $1 B$ ) and was blocked by glutamate receptor antagonists (10 $\mu \mathrm{M}$ DNQX + $25 \mu \mathrm{M}$ D-APV; Fig. $1 C$ ). Upon stronger LOT stimulation, a delayed outward synaptic current was often seen (Fig. $1 B$, right). This delayed response was a GABAergic IPSC, because its amplitude was increased as the membrane potential was shifted away from the $\mathrm{Cl}^{-}$reversal potential $(\sim-85 \mathrm{mV}$ with the $2 \mathrm{mM} \mathrm{Cl}^{-}$internal solution used here; Fig. $1 B$, bottom right) and it was blocked by the $\mathrm{GABA}_{\mathrm{A}}$ receptor antagonist bicuculline (Bic, $10 \mu \mathrm{M}$; Fig. 1C). Similar results were obtained in $n=25 \mathrm{SL}$ cells and $n=13$ SP cells (see also Luna and Schoppa, 2008; Stokes and Isaacson, 2010). This IPSC presumably arises from a mixture of feedforward and feedback inhibition (Fig. 1A). The aim of the work presented here was to identify the circuits and interneurons responsible for this inhibition. 


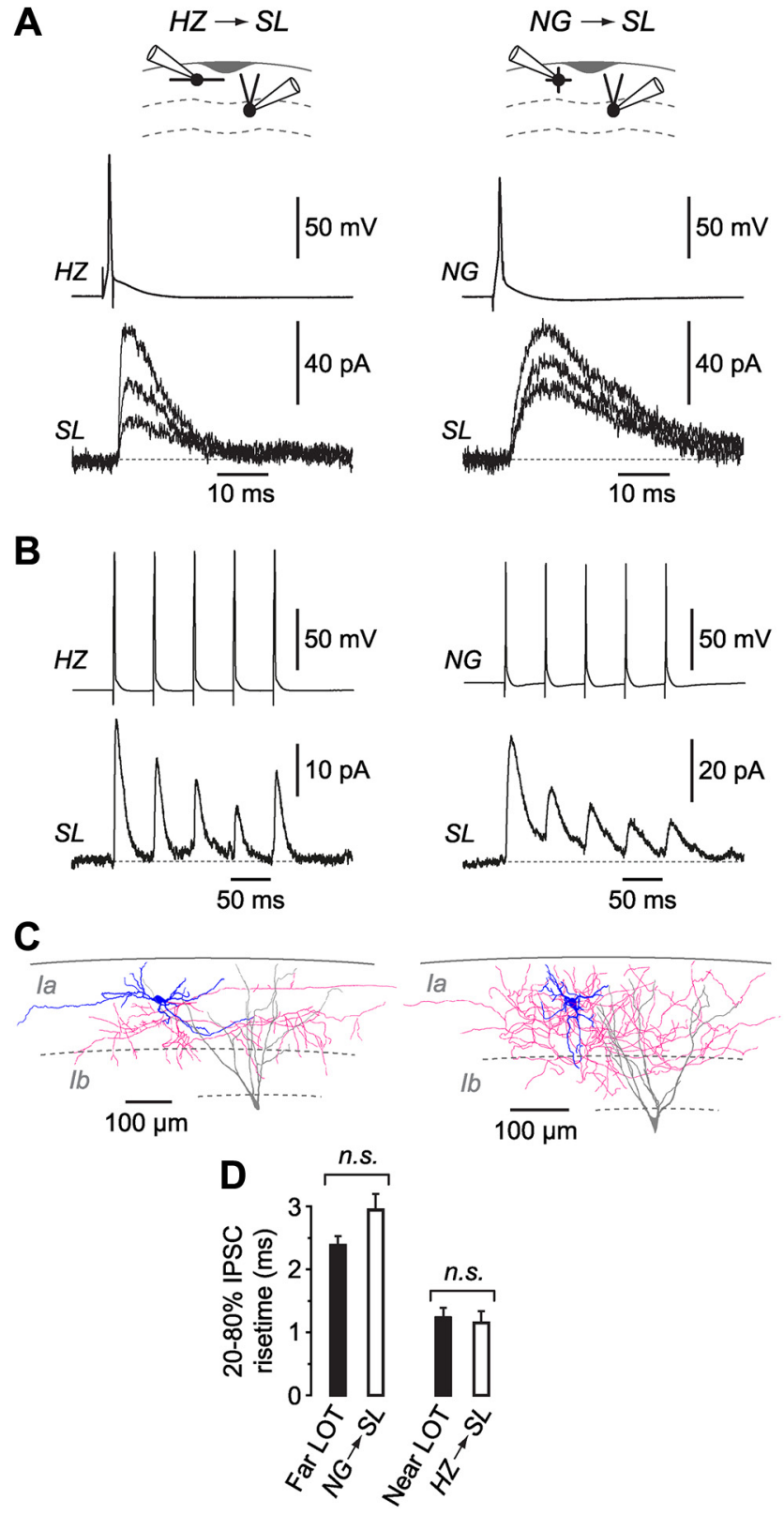

Figure 3. Pair recordings confirm that feedforward inhibition is provided by two classes of GABA-releasing interneurons in layer la, $\mathrm{HZ}$ cells and NG cells. $A-C$, Data from the same $\mathrm{HZ} / \mathrm{SL}$ cell pair (left column) and the same NG/SL cell pair (right column), all located near the LOT. $\boldsymbol{A}$, Upper traces show the presynaptic AP in the HZ cell (left) or NG cell (right); lower traces show IPSCS (three single episodes superimposed) in the postsynaptic SL cells. Holding potential for the SL cells was $+3 \mathrm{mV}$. B, Upper traces show a train of five APs at $20 \mathrm{~Hz}$ applied to the $\mathrm{HZ}$ cell (left) or NG cell (right); lower traces show the resultant IPSCs recorded in the SL cells (average of 20 episodes). $\boldsymbol{C}$, Morphologies of the cells from which the recordings in $\boldsymbol{A}$ and $\boldsymbol{B}$ were obtained. Blue, Presynaptic (HZ orNG) cell dendrites; red, presynaptic cell axon; gray, postsynaptic SL cell dendrites. D, Summary of mean ( \pm SEM) $20-80 \%$ rise time of IPSCS, measured for IPSCs obtained using either extracellular stimulation (Far LOT and Near LOT, as in Fig. 2; filled bars) or pair recordings (NG $\rightarrow \mathrm{SL}, \mathrm{HZ}$ $\rightarrow \mathrm{SL}$, as in $\boldsymbol{A}$ and $\boldsymbol{B}$; open bars). n.s., Not significantly different $(p>0.05$ ).

\section{Two types of feedforward inhibition can be observed in the} upper layers of the PC

We began by focusing on feedforward inhibition. It seemed likely that the interneurons involved (Fig. $1 A$, IN1) would possess dendritic trees that ramified significantly within layer Ia, where they could intercept excitatory aff fibers. We have previously reported that there are two types of interneurons that fit this description: HZ cells and layer Ia NG cells (Fig. 3C; Suzuki and Bekkers, 2010b). Both of these cell types receive strong excitatory input from the LOT, and their axonal arbors are dense within layer I, where they likely form inhibitory synapses on the distal dendrites of layer II/III principal neurons (Suzuki and Bekkers, 2010b). To test whether these axons could provide feedforward inhibition of principal neurons, whole-cell recordings were made from SL or SP cells while applying extracellular stimulation to the LOT/layer Ia border. These experiments were done in the presence of blockers of excitatory synaptic transmission $(10 \mu \mathrm{M}$ DNQX $+25 \mu \mathrm{M}$ $\mathrm{D}-\mathrm{APV}$ ) to prevent contamination by feedback inhibition (Fig. $1 A$, i.e., IN2).

When recording and stimulating far from the LOT $(>400$ $\mu \mathrm{m})$ in coronal slices, a slow-rising synaptic current was recorded in SL and SP cells for a wide range of stimulus strengths (Fig. $2 \mathrm{~A}$, left; stimulus range 5-60 $\mu \mathrm{A}$ for different cells; rise-time data for this cell are shown in Fig. $2 \mathrm{~B}$, left; mean $20-80 \%$ rise time of IPSCs in $n=8$ cells, $2.39 \pm 0.14 \mathrm{~ms}$ ). In contrast, when recording and stimulating close to the LOT $(<100 \mu \mathrm{m})$, stronger stimulation $(>15 \mu \mathrm{A})$ increasingly recruited a fast-rising synaptic current in addition to the slow-rising response (Fig. $2 \mathrm{~A}$, right; arrowheads indicate top of fast-rising current and arrows point to superimposed slow-rising current; rise-time data for this cell are shown in Fig. $2 \mathrm{~B}$, right; mean $20-80 \%$ rise time of fast current in $n=10$ cells, $1.23 \pm 0.16 \mathrm{~ms}$; significantly different from slow current, $p<0.001)$. Both slow- and fast-rising synaptic currents were completely blocked by bicuculline (10 $\mu \mathrm{M}$; data not shown), confirming that both were mediated by $\mathrm{GABA}_{\mathrm{A}}$ receptors. Moreover, both occurred at a brief latency after the stimulus, indicating that they likely arose from a monosynaptic connection (slow: $2.16 \pm 0.08 \mathrm{~ms}, n=7$ cells; fast: $1.61 \pm 0.08 \mathrm{~ms}, n=8$ cells). Thus, the fast- and slow-rising IPSCs were both probably due to the direct stimulation of GABA-releasing axons within layer Ia.

Pair recordings confirm that horizontal and neurogliaform cells produce feedforward inhibition

What could be the explanation for the two kinetic classes of IPSCs (fast-rising near the LOT, slow-rising both near and far)? We have previously reported that $\mathrm{HZ}$ cells are strictly localized in layer Ia close to the LOT, whereas NG cells are uniformly distributed throughout layer Ia (Suzuki and Bekkers, 2010b). Hence, we hypothesized that the fast- and slow-rising IPSCs were generated by $\mathrm{HZ}$ and NG cells, respectively. This was tested by making connected pair recordings from a presynaptic $\mathrm{HZ}$ or NG cell in layer Ia and a postsynaptic SL or SP cell in layer II (Fig. $3 A, B$; morphologies of the same cells are shown in Fig. $3 C$ ). In each case the postsynaptic response was completely blocked by bicuculline (10 $\mu \mathrm{M}$; data not shown), confirming that it was an IPSC mediated by $\mathrm{GABA}_{\mathrm{A}}$ receptors.

As predicted, the IPSCs recorded from these unitary connections were fast-rising when the presynaptic neuron was an $\mathrm{HZ}$ cell (Fig. 3A, left; mean $20-80 \%$ rise time $1.15 \pm 0.18 \mathrm{~ms}, n=3$ ) and slow-rising when the presynaptic neuron was an NG cell (Fig. $3 A$, right; $2.95 \pm 0.25 \mathrm{~ms}, n=7 ; p<0.01$ ). These rise times were not significantly different from the rise times of the fast and slow IPSCs evoked with extracellular stimulation (Fig. 3D). The results suggest that the distinctive synaptic properties of $\mathrm{HZ}$ and NG cells can explain the two kinetic variants of feedforward IPSCs.

Note that the extracellular stimulation experiments in the previous section (Two types of feedforward inhibition can be observed in the upper layers of the PC) left open the possibility that we were exciting GABA-releasing axons that sometimes ascend into layer Ia from interneurons located in deeper layers (Suzuki 
and Bekkers, 2010b). However, the pair recording experiments in this section indicate that axons from deeper neurons are not necessary to account for our findings.

NG $\rightarrow$ SL/SP cell unitary connections were readily found in our slices ( 13 connections out of 35 pairs tested; $37 \%$ connectivity), while $\mathrm{HZ} \rightarrow \mathrm{SL} / \mathrm{SP}$ cell connections were less common (3/50; $6 \%$ connectivity). These connectivities were significantly different $\left(p<0.001 ; \chi^{2} 2 \times 2\right.$ contingency test). The mean postsynaptic IPSC conductance was similar for both HZ and NG cells (HZ: mean conductance, $920 \pm 250 \mathrm{pS}, n=3$ cells; NG: $680 \pm$ $110 \mathrm{pS}, n=7 ; p=0.43$ ). These results, together with the observation that $\mathrm{HZ}$ cells are restricted to regions close to the LOT (Suzuki and Bekkers, 2010b), suggest that NG cells provide a more ubiquitous form of feedforward inhibition. The application of trains of presynaptic action potentials $(5-100 \mathrm{~Hz})$ showed that both HZ and NG cells produced depressing IPSCs in postsynaptic principal neurons, but the depression was more profound for NG cells. For example, in a $20 \mathrm{~Hz}$ train (Fig. 3B) the amplitude of the fifth IPSC, normalized to the amplitude of the first IPSC, was reduced to $18.7 \pm 4.0 \%(n=7)$ for NG cells but to only $57.5 \pm$ $3.3 \%(n=3 ; p<0.001)$ for HZ cells.

We have previously described three other classes of GABAergic interneurons in the PC (Suzuki and Bekkers, 2010b), one of which, the bitufted (BT) cell, can also extend its dendrites into layer Ia. Thus, it is possible that BT cells could also receive aff excitation and generate feedforward inhibition. However, using extracellular stimulation we previously found that the layer Ia excitation received by BT cells ( $17 \pm 4 \mathrm{pA}, n=7)$ is considerably weaker than that received by HZ cells $(1130 \pm 256 \mathrm{pA}, n=6, p<$ $0.01)$ and layer Ia NG cells $(212 \pm 57 \mathrm{pA}, n=4, p<0.01$; all measured at a holding potential of $-77 \mathrm{mV}$; Suzuki and Bekkers, 2010b). Moreover, as shown below, BT cells fire action potentials much more reluctantly following LOT stimulation than do other cell types, and the connectivity from BT cells to layer II principal neurons is weak. For all of these reasons, it is unlikely that BT cells make a significant contribution to feedforward inhibition.

In summary, feedforward inhibition engages two kinds of interneuron, namely, $\mathrm{HZ}$ cells, which provide inhibition close to the LOT, and layer Ia NG cells, which provide a more diffuse and slowly rising form of feedforward inhibition throughout the aff layer.

\section{A tissue cut enables isolation of feedback inhibition in deeper layers of the PC}

We next turned to feedback synaptic inhibition, which is hypothesized to arise from interneurons found in deeper assn layers (IN2, Fig. 1A). To remove contamination by feedforward inhibition, a cut was made across the LOT and layer Ia (Fig. $4 A$; the LOT is visible as a dark band at the upper margin of the parasagittal slices used in these experiments). A recording was then made from an SL or SP cell and a stimulating electrode was placed in the LOT either on the same side of the cut (Fig. $4 A$, left) to stimulate all inputs, or on the far side of the cut (Fig. $4 \mathrm{~A}$, right) to eliminate feedforward inhibition within superficial layers. For all recordings, the postsynaptic cell was voltage clamped at $+3 \mathrm{mV}$ to minimize the EPSC amplitude, and complete blockade of the IPSC by bicuculline $(10 \mu \mathrm{M})$ was confirmed at the end of the experiment. In other experiments, addition of glutamate receptor antagonists ( $10 \mu \mathrm{M}$ DNQX $+25 \mu \mathrm{M}$ D-APV) also blocked the IPSC, confirming that it involved feedforward synaptic excitation (not illustrated). Weak ("minimal") extracellular stimulation was used to excite one or a few axons (Materials and Methods).

First, with the stimulating electrode on the proximal side of the cut (Fig. 4, left column), a complex polysynaptic IPSC was
A

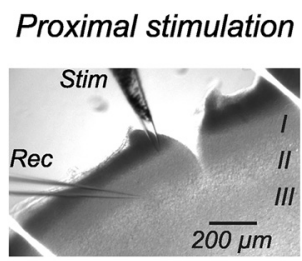

Distal stimulation

B
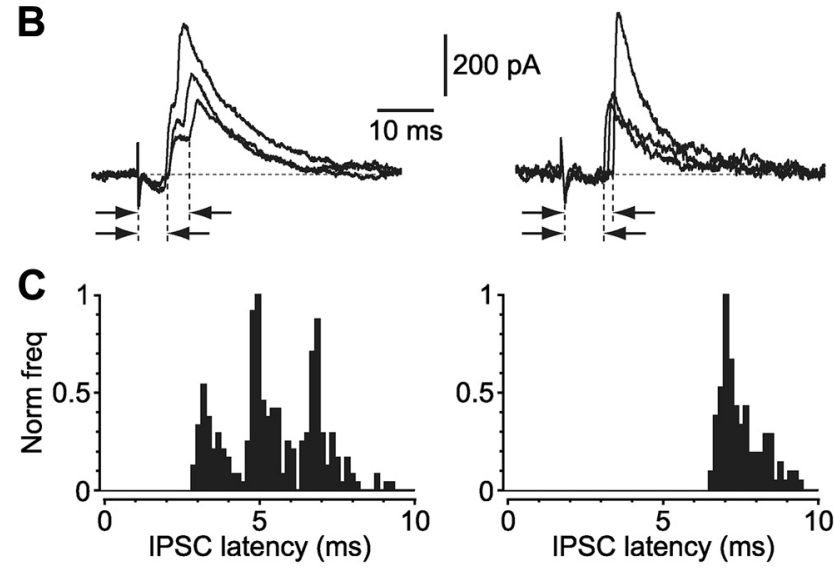

Figure 4. Transection of the LOT and layer la allows isolation of feedback inhibition mediated by interneurons in deeper layers. $\boldsymbol{A}-\boldsymbol{C}$, Data from an experiment in which the stimulating electrode was placed either on the same side of the tissue cut as the recording electrode (proximal stimulation, left column) or on the far side of the cut (distal stimulation, right column). $\boldsymbol{A}$, Images of the two recording configurations. The LOT is visible as a dark band along the margin of this parasagittal slice. A cut extends across the LOT and layer la, and partially into layer lb in this example. The recording electrode (Rec) is on an SL cell; the stimulating electrode (Stim) is placed with its tip at the LOT/la border, either on the proximal (left) or distal (right) side of the cut. $\boldsymbol{B}$, Evoked synaptic currents recorded with the two stimulus configurations in $\boldsymbol{A}$. Three responses are shown superimposed. Holding potential $+3 \mathrm{mV}$. Stimulus artifacts have been clipped. C, Histograms of latencies from the stimulus to the foot of each resolvable IPSC (arrows, B), measured for either proximal (left) or distal (right) stimulation. All data in this figure were obtained from the same postsynaptic SL cell.

recorded in the SL/SP cell (Fig. $4 B$, left), similar to that observed without a tissue cut (Fig. 1B). The delay between the stimulus and the foot of all clearly discernable components of this IPSC (arrows, Fig. $4 B$, left) was $>3 \mathrm{~ms}$ and appeared to contain at least three distinctive latency components in this example (3 peaks in latency histogram in Fig. 4C, left; overall mean latency $5.41 \pm$ $0.09 \mathrm{~ms}, n=107$ trials). We hypothesized that the earlier components arose from disynaptic feedforward inhibition following LOT stimulation (IN1, Fig. $1 A$; not to be confused with the monosynaptic feedforward inhibition in Fig. 2 in which interneuron axons were directly stimulated; such direct-axon stimulation was not present in Fig. 4). We further hypothesized that the longer-latency IPSCs (Fig. $4 B$, left) resulted from polysynaptic feedback inhibition involving interneurons in deeper layers.

These hypotheses were tested by moving the stimulating electrode to the distal side of the tissue cut to eliminate direct connections within the aff layer (Fig. 4, right column). Now the synaptic response was much simpler, i.e., only the longest-latency IPSCs were present (Fig. $4 B$, right), occurring with a delay-toonset $>6 \mathrm{~ms}$ (Fig. $4 C$, right; mean latency $7.53 \pm 0.06 \mathrm{~ms}, n=$ 115 trials; significantly greater than overall mean latency in Fig. $4 C$, left, $p<0.001$ ). This result suggests that feedforward inhibition can, indeed, be selectively ablated using a tissue cut, leaving a delayed synaptic response that is mediated by feedback inhibition. Similar results were obtained in 13 experiments of this kind, yielding a mean feedback latency of $7.00 \pm 0.20 \mathrm{~ms}$. These feed- 
back IPSCs had a mean amplitude of $108 \pm 25 \mathrm{pA}$ (with minimal stimulation; mean conductance $1540 \pm 360 \mathrm{pS}$ ), and their mean $20-80 \%$ rise time was $0.60 \pm$ $0.04 \mathrm{~ms}(n=13)$, significantly faster than both forms of feedforward inhibition (cf. Fig. 3D; HZ: 1.23-1.15 ms; NG: 2.39-2.95 $\mathrm{ms} ; p<0.001)$.

Stimulus-response plots implicate fastspiking cells in feedback inhibition Having identified IPSCs that likely result from feedback inhibition, we next sought to confirm and extend this finding by identifying the interneurons responsible. It is likely that these interneurons would be located in deeper layers of the PC, where they would preferentially receive excitatory input from assn fibers. We have previously reported that there are four main classes of GABAergic interneurons that match this description, namely, fastspiking multipolar (fMP) cells, regularspiking multipolar (rMP) cells, BT cells and deep-layer NG cells (Suzuki and Bekkers, 2010b). Our aim was to find which of these were the predominant sources of feedback inhibition.

One of these cell types, deep-layer NG cells, can be ruled out immediately. Recordings of unitary connections between deep-layer NG cells and SL/SP cells (below; see also Fig. $3 A$, right) showed that the $20-80 \%$ rise time of IPSCs generated by NG cells is slow $(3.48 \pm 0.24 \mathrm{~ms}, n=$ 12), much slower than the observed rise time of feedback IPSCs $(0.60 \pm 0.04 \mathrm{~ms}, n=13, p<0.001$; see A tissue cut enables isolation of feedback inhibition in deeper layers of the PC). Hence, we focused on the remaining three types of deep-layer interneurons, fMP, rMP and BT cells.

As illustrated schematically in Figure $1 A$, we are seeking a type of interneuron (IN2) that is reliably driven by a layer II principal neuron (SL or SP cell) following LOT stimulation. We have recently shown that SL cells receive the strongest aff input from the LOT (Suzuki and Bekkers, 2011; see also Wiegand et al., 2011); hence, it is likely that SL cells drive IN2 to generate feedback inhibition (Fig. 1A). (Further evidence for this statement will be given in Figure 6.) Therefore, in an initial series of experiments we measured the excitability of SL cells in response to LOT stimulation while simultaneously measuring the excitability of different classes of interneuron. We reasoned that interneurons that were as excitable as SL cells under these stimulus conditions were the most likely to be driven by SL cells, and hence the most likely candidates for providing feedback inhibition.

Focusing first on fast-spiking fMP cells, dual whole-cell current-clamp recordings were made from an SL cell and an fMP cell while stimulating the LOT (Fig. 5A, left). Increasing the stimulus strength (numbers above traces) eventually caused each cell to fire one or more APs. The response of each kind of cell to LOT stimulation was quantified by plotting the probability of firing at least one AP versus the stimulus strength (Fig. 5A, right; open symbols, SL cells; filled symbols, fMP cells; averages of $n=5$ dual recordings). This analysis showed that $\mathrm{fMP}$ cells started to fire at
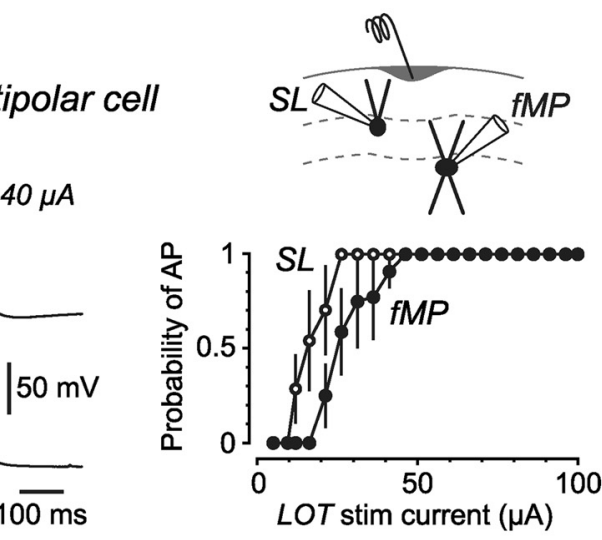

\section{A)}

B
$S L+$ regular-spiking multipolar cell
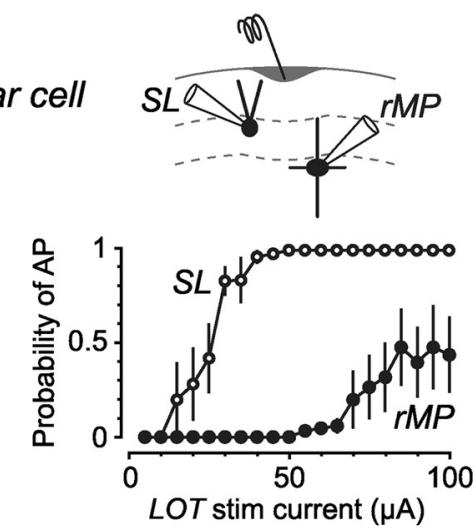

$100 \mathrm{~ms}$ ack inhibition is largely due to SL cells driving fMP cells. $A$, Left, Simultaneous current-clamp recordings from an SL cell (top) and an FMP cell (bottom) while applying a single stimulus to the LOT at three different stimulus intensities $(10,15,40 \mu \mathrm{A})$. Right, Summary of experiments like that at left, showing plots of the mean probability of firing at least one AP versus the LOT stimulus current for SL cells and fMP cells ( $n=5$ dual recordings). $\boldsymbol{B}$, Similar data for $S L$ and rMP cell dual recordings. The summary plots were calculated from $n=5$ experiments.

stimulus strengths that were only slightly greater than those required to fire SL cells (mean stimulus current required to generate at least one AP with a probability of 0.5 was $1.47 \pm 0.18$-fold higher in fMP cells compared with SL cells, $n=5$ dual recordings). This result is consistent with the existence of a strong excitatory connection from SL cells to fMP cells.

In contrast, when the same experiment was done with an SL/ rMP cell pair (Fig. 5B), it was found that rMP cells were much more reluctant to fire $(10.6 \pm 3.5$-fold higher stimulus current required in rMP cells than in SL cells; $n=7$ pairs; significantly different from fMP/SL cell pairs, $p<0.05$; Fig. $5 B$, right). This result suggests that regular-spiking rMP cells are not effectively recruited following LOT stimulation and, therefore, are less likely to contribute feedback inhibition. Similar results were obtained for BT cells (24.3 \pm 6.6 -fold higher stimulus current required in BT cells than in SL cells; $n=4$ pairs; significantly different from fMP/SL cell pairs, $p<0.05$; not illustrated). Hence, these results support the idea that fMP cells are responsible for generating most of the feedback inhibition under these stimulus conditions.

Synaptic and firing latencies confirm the involvement of fastspiking multipolar cells in feedback inhibition

If LOT $\rightarrow$ SL $\rightarrow$ fMP connections generate feedback inhibition, the time delay between stimulation of the LOT and the appearance of a feedback IPSC in a layer II principal cell ( $\sim 7 \mathrm{~ms}$, Fig. $4 C$, right) should be consistent with the chain of synaptic delays along 


\section{A Layer II principal cells}
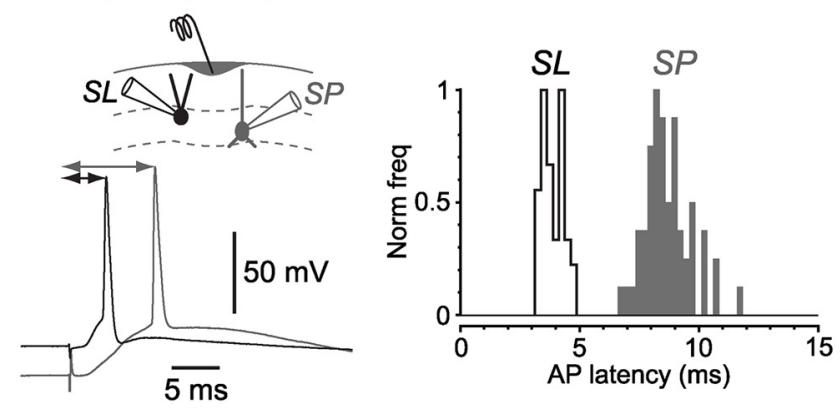

B Fast-spiking multipolar cell
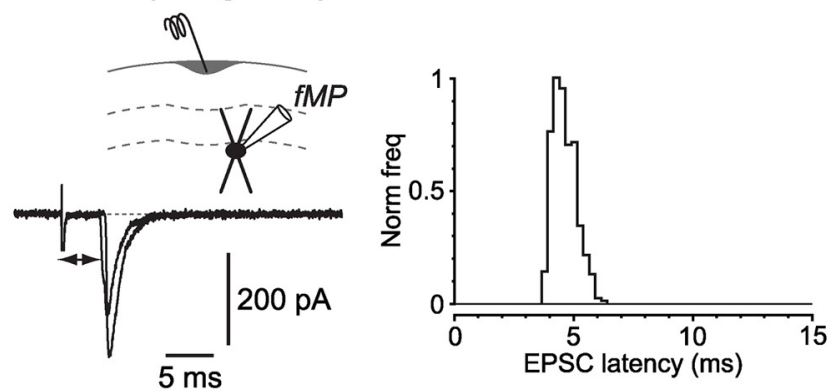

\section{Fast-spiking multipolar cell}
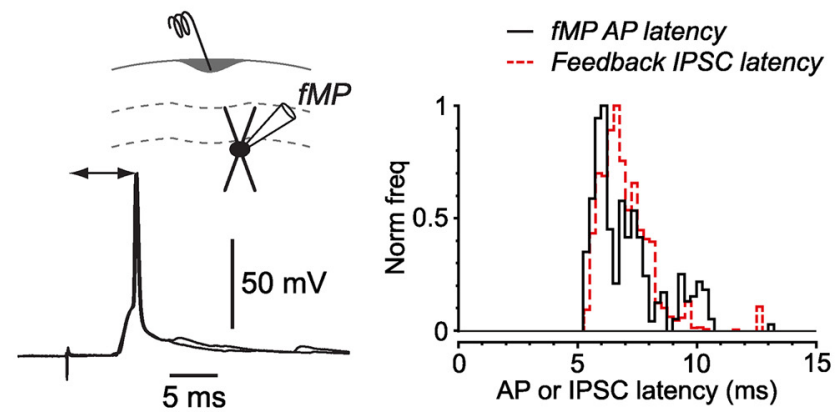

Figure 6. Measurements of the latencies of EPSCs and APs are consistent with the idea that fMP cells, driven by SL cells, provide feedback synaptic inhibition. $A$, Left, APs elicited by minimal stimulation of the LOT, measured in an SL cell (black trace) and an SP cell (gray trace). Right, Histograms of latencies between the time of the stimulus and the peak of the AP (arrowed in left-hand panel; combined measurements from $n=4 \mathrm{SL}$ cells and $n=4 \mathrm{SP}$ cells). Redrawn from Suzuki and Bekkers (2011). B, Left, Two EPSCs elicited by minimal LOT stimulation, recorded in an $\mathrm{fMP}$ cell. Stimulus artifacts have been clipped. Right, Histogram of latencies from the stimulus time to the foot of the EPSC (arrowed in left-hand panel; combined measurements from $n=10 \mathrm{fMP}$ cells). C, Left, Two APs elicited by minimal LOT stimulation, measured in an fMP cell. C, Right, Histogram of latencies from the stimulus time to the AP peak (arrowed in left-hand panel), shown as an unbroken line (combined measurements from $n=8 \mathrm{fMP}$ cells). Also shown (red dashed line) is the histogram of latencies of IPSCs responsible for feedback inhibition, measured from tissue-cut experiments like those in Figure 4C, right (combined measurements from $n=13$ cells).

this pathway. This idea was tested by measuring synaptic and firing latencies in the proposed circuit.

As noted earlier, SL cells are most likely the first neurons in the feedback inhibitory circuit because they receive the strongest LOT input (Suzuki and Bekkers, 2011; Wiegand et al., 2011). Additional evidence comes from measurements of firing latency. A whole-cell recording was made from either an SL or an SP cell while stimulating the LOT at an intensity just above threshold for eliciting a synaptically evoked action potential (Fig. 6A, left). As we have previously reported (Suzuki and Bekkers, 2006), the latency from the stimulus to the peak of the AP (arrows, Fig. $6 \mathrm{~A}$, left) was much briefer in SL cells (black trace) than in SP cells (gray trace). Histograms of this latency (Fig. 6A, right, redrawn from Suzuki and Bekkers, 2011) confirm that the AP latency in SL cells (mean $3.87 \pm 0.07 \mathrm{~ms}, n=4$ cells) is significantly smaller than that in SP cells $(8.69 \pm 0.13 \mathrm{~ms}, n=4 ; p<0.001)$. Critically, the mean AP latency in SP cells $(8.69 \mathrm{~ms})$ is greater than the mean latency of feedback IPSCs ( $\sim 7 \mathrm{~ms}$; Fig. $4 C$, right, and red dashed histogram, Fig. $6 C$, right), i.e., SP cells only fire after the appearance of feedback inhibition. These results confirm that SL cells, not SP cells, must drive feedback inhibition under these stimulus conditions.

The next neuron in the feedback inhibitory cascade (Fig. $1 A$, IN2) is proposed to be an fMP cell (see Stimulus-response plots implicate fast-spiking cells in feedback inhibition). A whole-cell voltage-clamp recording was made from an $\mathrm{AMP}$ cell while applying minimal stimulation to the LOT (Fig. $6 \mathrm{~B}$, left). Large, all-ornone EPSCs were observed (mean amplitude, $-123.2 \pm 29.1 \mathrm{pA}$, holding potential $-77 \mathrm{mV}, n=10$ cells). The latency between the stimulus and EPSC onset (arrow, Fig. 6B, left) had a mean value of $4.60 \pm 0.02 \mathrm{~ms}$ (Fig. $6 \mathrm{~B}$, right; combined data from $n=10$ cells). Hence, this fMP EPSC appears, on average, $4.60-3.87=0.73 \mathrm{~ms}$ after the mean time of occurrence of an AP in SL cells (3.87 ms; Fig. $6 A$ ), consistent with monosynaptic transmission from the SL to the fMP cell. (See also Fig. 7)

Next, a similar experiment was performed, but this time recording from the fMP cell in current-clamp mode. With minimal LOT stimulation, a large EPSP was elicited, and this could reliably evoke an AP in the fMP cell (Fig. 6C, left). The latency between the stimulus and the AP peak (arrow, Fig. $6 C$, left) had a broad distribution when averaged across different fMP cells (Fig. 6C, right; mean latency, $7.09 \pm 0.13 \mathrm{~ms}$, combined data from $n=8$ cells). This may be compared with the latency distribution for feedback IPSCs obtained from tissue-cut experiments like those in Figure 4, right (red dashed histogram, Fig. 6C, right; mean latency, $7.00 \pm 0.2 \mathrm{~ms}$, combined data from $n=13$ cells). Although these two histograms are dispersed, reflecting latency variability between the different cells included in the average, their similarity is consistent with the idea that monosynaptic transmission from $\mathrm{fMP}$ cells is able to generate the feedback inhibition in SL/SP cells that we observed in the tissue-cut experiments (Fig. 4, right).

In summary, measurements of synaptic and firing latencies, together with measurements of synaptic strength (Fig. 5), suggest that fMP cells, driven by SL cells, are the most likely candidates for providing feedback inhibition of layer II principal cells following minimal single-pulse stimulation of the LOT.

\section{Pair recordings confirm that layer II principal cells can provide feedforward excitation of layer III fast-spiking cells} If SL cells excite fMP cells to provide feedback inhibition, it should be possible to find unitary SL $\rightarrow$ fMP cell synaptic connections. Pair recordings showed that such connections were, indeed, present ( 5 of 31 pairs tested $=16 \%$ connectivity; Fig. $7 A, B$, left; morphologies of the same cells are shown in Fig. $7 C$, left). The postsynaptic response in the fMP cell was completely blocked by DNQX (10 $\mu \mathrm{M}$; data not shown), confirming that it was a glutamatergic EPSC. The unitary EPSC in the fMP cell was large $(-109.7 \pm 47.2 \mathrm{pA}$ at $-77 \mathrm{mV}$ holding potential; mean conductance $1425 \pm 613 \mathrm{pS}, n=5$ pairs) and not significantly different in amplitude from the EPSC measured in fMP cells above (see Synaptic and firing latencies confirm the involvement of fast-spiking multipolar cells in feedback inhibition) using extracellular LOT stimulation $(-123.2 \pm 29.1 \mathrm{pA} ; p=0.81)$. Moreover, the mean latency from the peak of the AP in the SL cell to 


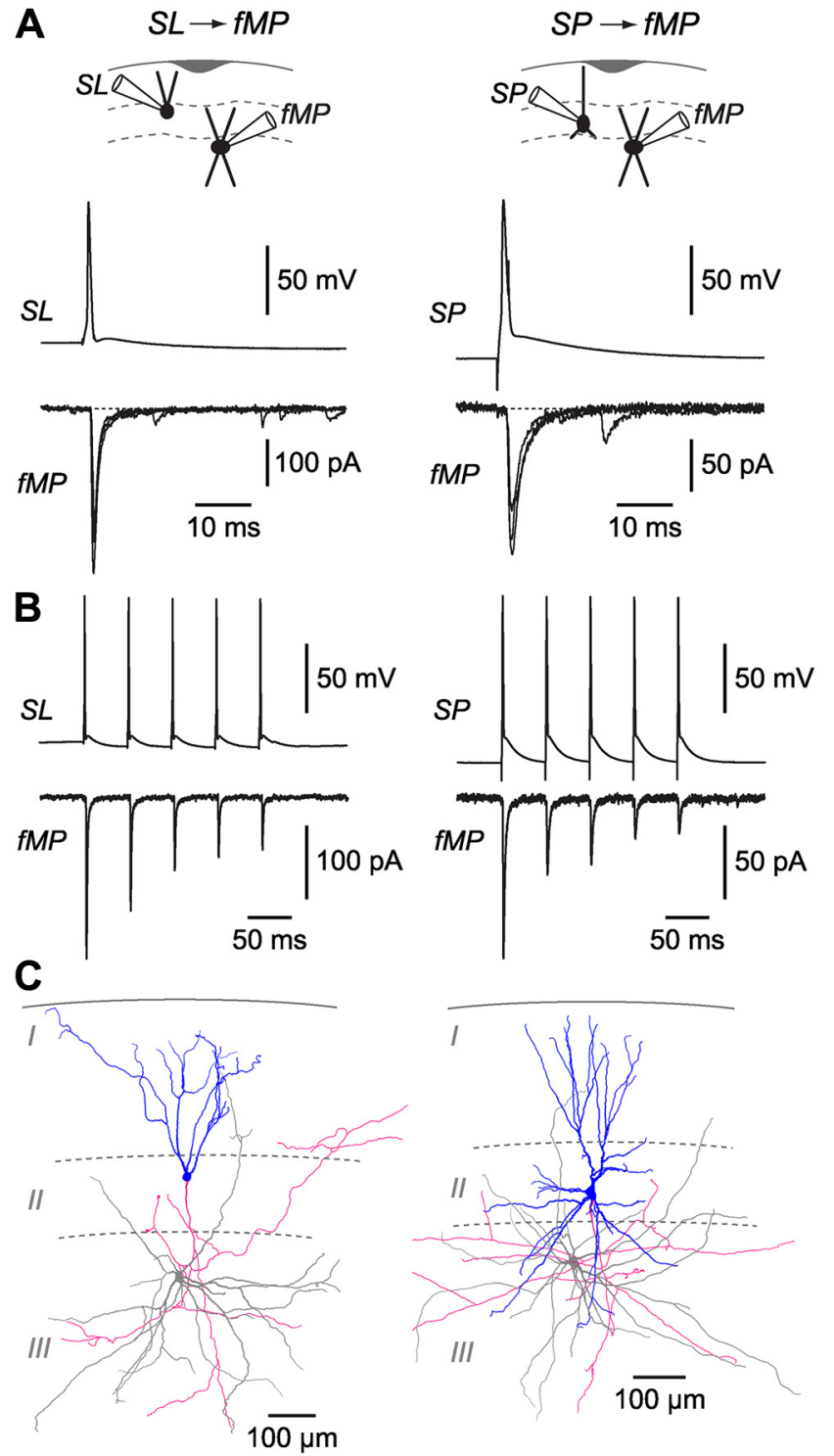

Figure 7. Pair recordings reveal feedforward excitatory connections from layer II principal cells to layer III fast-spiking cells. $A-C$, Data from the same SL/fMP cell pair (left column) and the same SP/fMP cell pair (right column). $\boldsymbol{A}$, Unitary EPSCs (bottom) in response to single presynaptic APs (top). Three episodes are superimposed. Holding potential in the postsynaptic $f M P$ cell was $-77 \mathrm{mV}$. B, Response of the same cell pairs to a $20 \mathrm{~Hz}$ train of presynaptic APs. Postsynaptic EPSC traces are averages of 12 (left) and 20 (right) episodes. C, Reconstructions of the cell pairs in $\boldsymbol{A}$ and $\boldsymbol{B}$ showing the dendrites (blue) and axons (red) of the presynaptic (SL or SP) cells, and the dendrites (gray) of the postsynaptic fMP cells.

the foot of the EPSC in the fMP cell was $0.83 \pm 0.10 \mathrm{~ms}$ ( $n=5$ cells), which is similar to the value estimated in the previous section (Synaptic and firing latencies confirm the involvement of fast-spiking multipolar cells in feedback inhibition) using extracellular stimulation $(0.73 \mathrm{~ms})$. SL-evoked unitary EPSCs in fMP cells also exhibited short-term depression (e.g., $20 \mathrm{~Hz}$ stimulus train, Fig. 7B, left; amplitude of the fifth EPSC normalized to the amplitude of the first EPSC, $26.2 \pm 4.0 \%, n=5$ ).

We also looked for unitary SP $\rightarrow$ fMP cell connections to test whether SP cells in layer IIb would also be capable of providing feedforward excitation of fMP cells. Such unitary connections were found ( 6 of 33 pairs tested $=18 \%$ connectivity; not significantly different from SL $\rightarrow$ fMP connectivity, $p>0.5, \chi^{2} 2 \times 2$ contingency test; Fig. $7 A-C$, right). Interestingly, these SP cell- generated EPSCs were very similar to those produced by SL cells: the mean amplitude was $-111.3 \pm 53.7 \mathrm{pA}$ at $-77 \mathrm{mV}$ (mean conductance $1445 \pm 697 \mathrm{pS}, n=6$ pairs; not significantly different from SL cell EPSCs, $p=0.98$ ), and the normalized depression after five stimuli at $20 \mathrm{~Hz}$ was $31.8 \pm 8 \%$ (not significantly different from SL cells, $n=5, p=0.53$ ). These results suggest that SP cells should be as capable as SL cells of exciting fMP cells to produce feedback inhibition, if all other factors were equal. However, we find here that SL cells preferentially drive feedback inhibition when the LOT is minimally stimulated, because SL cells are more strongly excited by LOT inputs under these conditions (Suzuki and Bekkers, 2011; Wiegand et al., 2011).

Unitary synaptic connections confirm the role of fast-spiking cells in feedback inhibition

Finally, we examined the last step in the proposed feedback inhibitory circuit (interneuron $\rightarrow$ SL or SP cell) by making recordings from synaptically connected pairs of these neurons. As expected from the extensive axonal arborization of fMP cells in layer II (Fig. 8C, left; Suzuki and Bekkers, 2010b), fMP $\rightarrow$ SL or SP connections were comparatively common (17 of 53 cell pairs tested $=32 \%$ connectivity) and powerful (mean synaptic amplitude at $+3 \mathrm{mV}, 137.6 \pm 31.4 \mathrm{pA}$, giving a mean conductance of $1965 \pm 449$ pS, $n=16$ pairs; Fig. 8 A, left). The $20-80 \%$ rise time of IPSCs generated by presynaptic fMP cells was rapid $(0.69 \pm$ $0.05 \mathrm{~ms}, n=16$ ), as expected for perisomatic basket-type connections, and similar to the rise time measured for feedback IPSCs in the tissue-cut experiments $(0.60 \pm 0.04 \mathrm{~ms}$; not significantly different, $p=0.18$ ). Trains of fMP IPSCs evoked at $20 \mathrm{~Hz}$ depressed moderately during the train (Fig. 8B, left; amplitude of the fifth IPSC normalized to the amplitude of the first IPSC, $52.4 \pm 4.0 \%, n=9$ ).

In contrast, both $\mathrm{rMP} \rightarrow \mathrm{SL} / \mathrm{SP}$ and $\mathrm{BT} \rightarrow \mathrm{SL} / \mathrm{SP}$ connections were less common than fMP connections (rMP: $3 / 31=10 \%, p=$ 0.02 ; BT: $4 / 44=9 \%, p<0.01 ; \chi^{2} 2 \times 2$ contingency test) and, when found, were weaker (rMP: $29.2 \pm 8.4 \mathrm{pA}$ at $+3 \mathrm{mV}$, conductance $420 \pm 120 \mathrm{pS}, n=3$ pairs, $p=0.004$, Fig. 8 , right; BT: $20.2 \pm 0.3 \mathrm{pA}$ at $+3 \mathrm{mV}$, conductance $290 \pm 4 \mathrm{pS}, n=4$ pairs, $p=0.002$, not illustrated). Their IPSC $20-80 \%$ rise times were also slower than those found for fMP cells (rMP: $1.56 \pm 0.52 \mathrm{~ms}$, $n=3, p=0.002$; BT: $1.54 \pm 0.22 \mathrm{~ms}, n=4, p<0.001)$. Trains of IPSCs evoked at $20 \mathrm{~Hz}$ in rMP and BT cells showed similar depression to that seen for fMP cells (normalized amplitude of fifth IPSC: rMP, $61.5 \pm 18.6 \%, n=3, p=0.45$, Fig. $8 B$, right; BT: $53.9 \pm 10.7 \%, n=3, p=0.38$, not illustrated).

Connections from deeper (layers Ib, II, III) NG cells to SL/SP cells were, as in layer Ia, relatively easy to find $(19 / 31=61 \%)$. However, the rise times of their IPSCs were, like those of layer I NG cells (Fig. $3 A$, right), very slow ( $3.48 \pm 0.24 \mathrm{~ms}, n=12)$, ruling them out as possible contributors to fast feedback inhibition of the kind observed in the tissue-cut experiments (Fig. 4).

\section{Dynamic clamp simulations reveal different effects of feedback inhibition on SL and SP cells}

What are the functional roles of the inhibitory circuits we have identified? We focused on the effects of inhibition on the likely main targets, the layer II principal neurons. We first needed to measure the reversal potential for GABAergic IPSPs in these layer II neurons. This was done by using gramicidin-perforated patch clamping to avoid perturbing the native intracellular chloride concentration (Gulledge and Stuart, 2003; Materials and Methods). Brief puffer application of GABA to the soma then allowed estimation of the reversal potential for ion flux through $\mathrm{GABA}_{\mathrm{A}}$ channels (not illustrated). The 
A

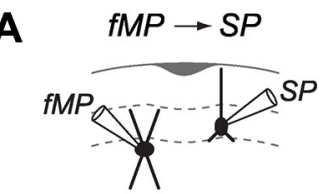<smiles>CC(C)CC(C)C</smiles>
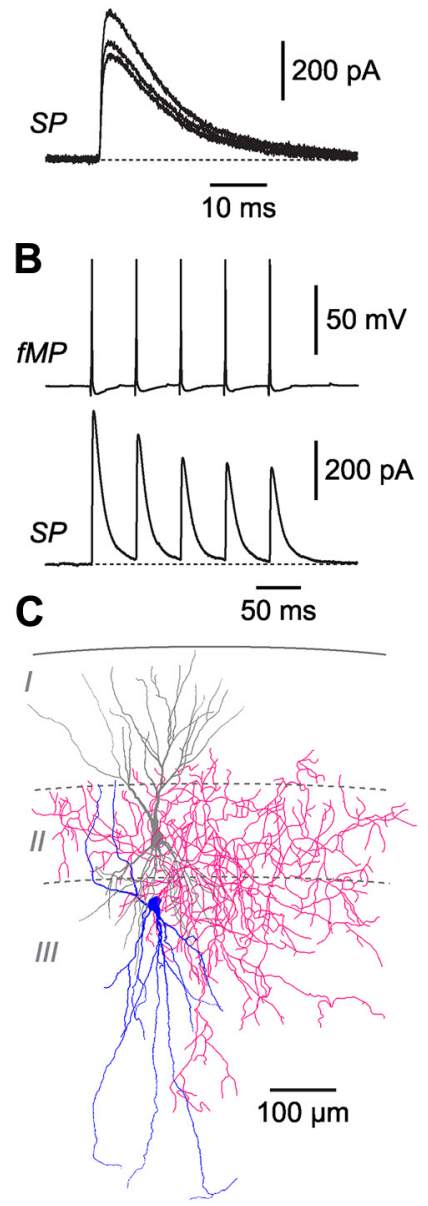

Figure 8. Pair recordings confirm that $\mathrm{fMP}$ cells make strong unitary connections onto layer Il principal cells, whereas rMP and BT cells make weak connections. $A-C$, Data from the same fMP/SP cell pair (left column) and the same rMP/SP cell pair (right column). $A$, Unitary IPSCS (bottom) in response to single presynaptic APs (top). Three episodes are superimposed. Holding potential in the postsynaptic SP cell was +3 $\mathrm{mV}$. $\boldsymbol{B}$, Response of the same cell pairs to a $20 \mathrm{~Hz}$ train of presynaptic APs. Postsynaptic IPSC traces are averages of 20 episodes. $\boldsymbol{C}$, Reconstructions of the cell pairs in $\boldsymbol{A}$ and $\boldsymbol{B}$ showing the dendrites (blue) and axons (red) of the presynaptic (fMP or rMP) cells, and the dendrites (gray) of the postsynaptic SP cells.

results for SL and SP cells were similar; hence, the data were combined, yielding a mean $\mathrm{GABA}_{\mathrm{A}}$ IPSP reversal potential of $-84.7 \pm$ $3.7 \mathrm{mV}(n=6)$.

Because the gramicidin experiments reported the $\mathrm{GABA}_{\mathrm{A}}$ reversal potential at the soma, we only examined the functional role of feedback inhibition via fMP cells, which is perisomatic (Suzuki and Bekkers, 2010b). A whole-cell recording was made from either an SL or SP cell and an EPSP was evoked by stimulating the LOT (Fig. 9). The bath solution contained picrotoxin $(100 \mu \mathrm{M})$ to block synaptic inhibition but no other blockers. Somatic feedback inhibition was then reinstated using a dynamic clamp to inject via the somatic patch electrode an inhibitory postsynaptic conductance (IPSG) modeled on the measured feedback synaptic
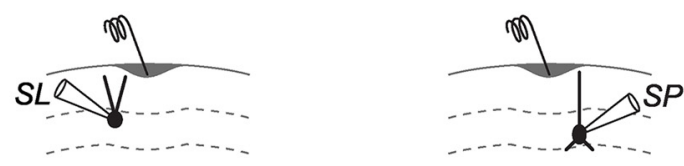

\section{A Subthreshold EPSPS}
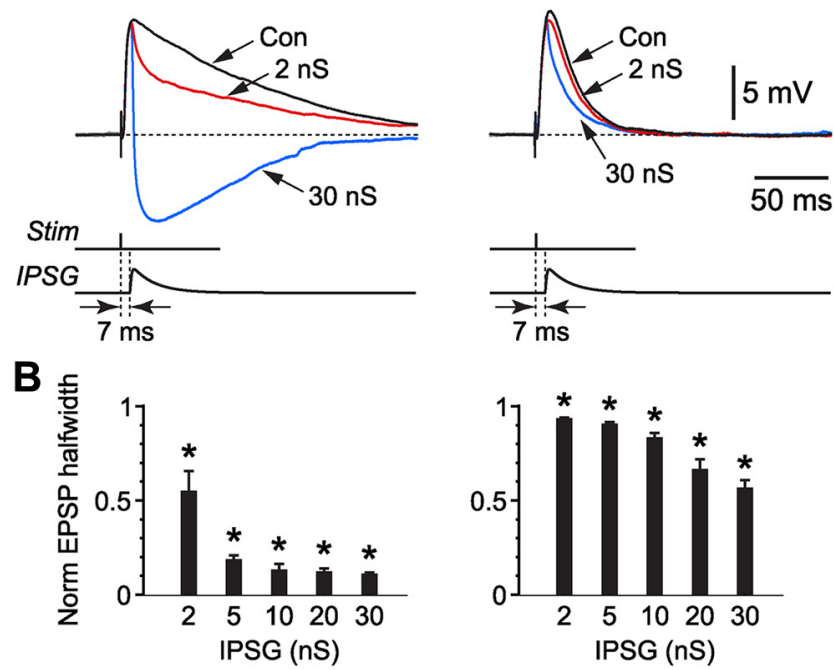

C Suprathreshold EPSPS
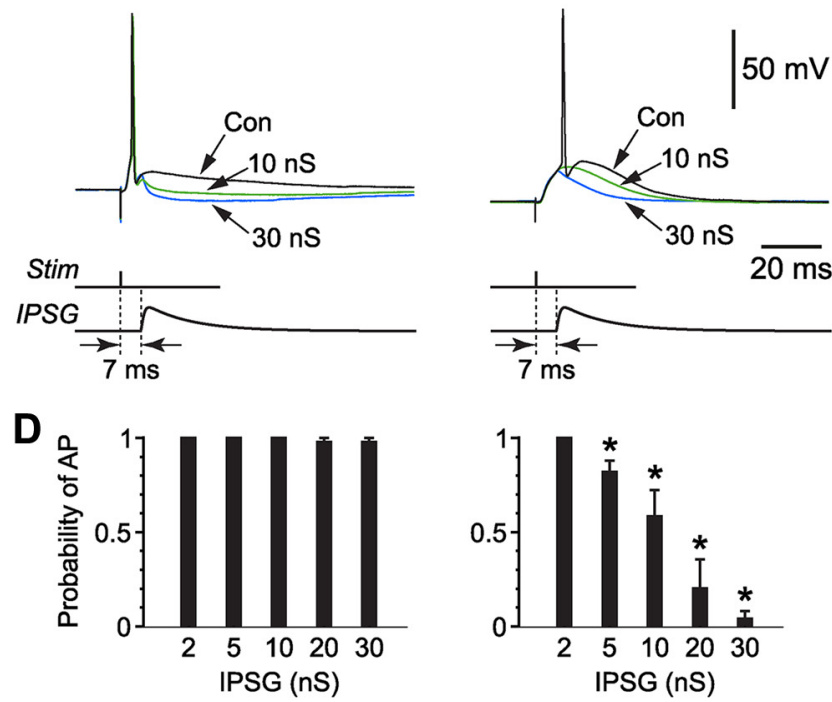

Figure 9. SL and SP cells respond differently to feedback synaptic inhibition simulated using a dynamic clamp at the soma. $\boldsymbol{A}-\boldsymbol{D}$, Left-hand panels show data from SL cells, right-hand panels from SP cells. A, Subthreshold EPSPs evoked by LOT stimulation, either a control trace with no inhibition (black) or traces with two strengths of inhibition (colors; peak inhibitory conductance, $2 \mathrm{nS}$ or $30 \mathrm{nS}$ ). Traces at bottom show the timing of the LOT stimulus (Stim) and the IPSG. Each EPSP trace is an average of 3-10 episodes. Stimulus artifacts have been clipped. Calibration bars at right also apply to left-hand panels. Note that traces have been baselined; the resting potential of the SP cell is actually more hyperpolarized than that of the SL cell. $\boldsymbol{B}$, Summary bar plots for experiments like those in $\boldsymbol{A}$, showing the mean EPSP half-width in the presence of the indicated peak IPSG, normalized to the control half-width in the same cell in the absence of simulated inhibition. C, Suprathreshold EPSPs showing, in some traces, superimposed action potentials. Details otherwise as for $\boldsymbol{A}$. $\boldsymbol{D}$, Summary bar plots for experiments like those in $\boldsymbol{C}$, showing the mean probability of eliciting an action potential in the presence of the indicated peak IPSG. In the absence of inhibition (data not shown), an action potential was always elicited in both cell types. Each bar in $\boldsymbol{B}$ and $\boldsymbol{D}$ is an average of $n=3-6$ cells; asterisk indicates significant difference from unity $(p<0.05)$. 
current (Fig. 9A; Materials and Methods). The latency of this simulated inhibition was initially set at the mean latency for feedback IPSCs obtained from the tissue-cut experiments in Figure 4 (i.e., $7 \mathrm{~ms}$ following LOT stimulation; Fig. 9A, traces labeled Stim and IPSG). The reversal potential of this inhibition was fixed at $-85 \mathrm{mV}$, as found in the gramicidin experiments. The only free parameter was the peak amplitude of the IPSG, which was varied systematically.

We began by measuring the effect of simulated feedback inhibition on EPSPs that were subthreshold for firing an action potential (Fig. 9A). Injecting $2 \mathrm{nS}$ of inhibitory conductance (approximately the input from a single fMP cell; see Unitary synaptic connections confirm the role of fast-spiking cells in feedback inhibition) had a dramatic effect on SL cells, accelerating the decay of the EPSP and significantly reducing its half-width by nearly one-half (from $63.2 \pm$ $14.6 \mathrm{~ms}$ to $37.1 \pm 14.5 \mathrm{~ms}, n=4, p=0.039$, paired $t$ test; or to $0.54 \pm$ 0.11 of the control half-width; red trace, Fig. $9 A, B$, left). In contrast, the same conductance had a much smaller (but still significant) effect on the EPSP in SP cells (half-width reduced from $19.3 \pm 2.0 \mathrm{~ms}$ to $17.9 \pm 1.8 \mathrm{~ms}, n=4, p=0.017$, paired $t$ test; or $0.93 \pm 0.01$ of control; red trace, Fig. $9 A, B$, right). This difference between SL and SP cells is expected, because SL cells have a higher input resistance and a more depolarized resting potential (Suzuki and Bekkers, 2006, 2011), which together magnify the effect of an inhibitory conductance. Increasing the IPSG to $30 \mathrm{nS}$ further attenuated the EPSP half-width in SL cells (to $5.2 \pm 0.3 \mathrm{~ms}$, or $0.10 \pm 0.01$ of control; blue trace, Fig. 9A, $B$, left), whereas it had a much more modest effect in SP cells (reduced to $11.0 \pm 1.1 \mathrm{~ms}$, or $0.56 \pm 0.05$ of control; blue trace, Fig. $9 A, B$, right). By accelerating the decay of EPSPs, feedback inhibition also reduced the temporal summation of EPSPs, with this effect being much more pronounced in SL cells than in SP cells (Fig. $10 A$; SL: summation reduced to $0.78 \pm 0.03$ of control, $n=4$; SP: paired-pulse facilitation reduced to $0.97 \pm 0.03$ of control, $n=3$; SL and SP cells significantly different, $p=0.007$; all with interstimulus interval $50 \mathrm{~ms}$ and IPSG $5 \mathrm{nS}$ ).

We next repeated this experiment using suprathreshold EPSPs (Fig. 9C). Stimulation of the LOT was increased until synaptically evoked APs could reliably be elicited in the absence of inhibition (Fig. 9C, black traces), then simulated feedback inhibition was switched on (Fig. 9C, colored traces). Increasing the amplitude of the IPSG had little effect on the probability of AP firing in SL cells (Fig. 9C,D, left). In contrast, firing in SP cells was progressively attenuated (Fig. 9C,D, right). This difference is easily understood: SL cells fire synaptically evoked APs early enough after synaptic stimulation (latency $\sim 3.9 \mathrm{~ms}$; Fig. $6 \mathrm{~A}$ ) that they precede, and hence escape, feedback inhibition (which here occurs with latency $\sim 7 \mathrm{~ms}$; Fig. 4C). On the other hand, SP cells fire synaptically evoked APs with a longer latency $(\sim 8.7 \mathrm{~ms}$; Fig. $6 A)$, late enough that their spikes are intercepted by feedback inhibition.

Finally, we examined the effect of changing the latency of feedback inhibition on spiking probability in SL and SP cells (Fig. $10 B, C)$. Again, LOT stimulus strength was adjusted to reliably evoke APs without inhibition (black traces, Fig. $10 \mathrm{~B}$ ), then simulated feedback inhibition (fixed at $30 \mathrm{nS}$ ) was applied with different latencies after the stimulus (3-7 ms; colored traces, Fig. $10 \mathrm{~B})$. As expected, spiking was abolished in SP cells for all latencies (Fig. $10 B, C$, right). In contrast, spiking in SL cells was affected only by reducing the latency of inhibition to $3 \mathrm{~ms}$, i.e., brief enough to attenuate the peak of the fast-rising EPSP in these cells (Fig. $10 B, C$, left).

In summary, simulated feedback inhibition has opposite effects on SL and SP cells, attenuating EPSP half-width more strongly in SL cells and inhibiting APs more strongly in SP cells.
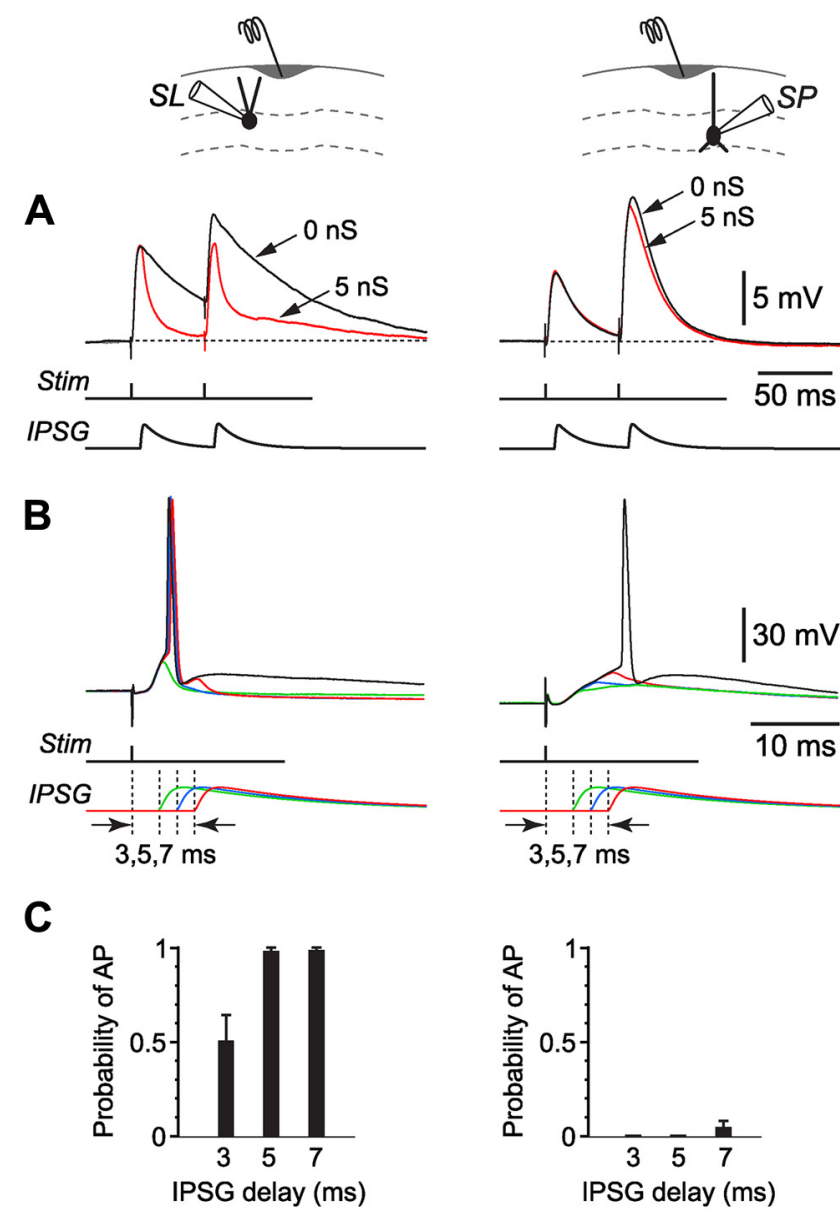

Figure 10. SL and SP cells show different types of temporal sensitivity in the presence of simulated feedback inhibition. $\boldsymbol{A}$, Responses of an SL cell (left) and an SP cell (right) to two subthreshold stimuli applied to the LOT (50 ms interval), either without (black traces) or with (red traces) an IPSG (5 nS) injected at the soma using the dynamic clamp. The IPSG starts $7 \mathrm{~ms}$ after each stimulus. Inhibition strongly reduces temporal summation in the SL cell, but has little effect on paired-pulse facilitation in the SP cell. $\boldsymbol{B}$, Responses of an SL cell (left) and an SP cell (right) to a suprathreshold stimulus applied to the LOT while varying the latency between the stimulus and the IPSG (colored traces; delay 3, 5, $7 \mathrm{~ms}$; IPSG = $30 \mathrm{nS}$ ). The black traces are the responses in the absence of the IPSG. $\boldsymbol{C}$, Summary of experiments like those in $\boldsymbol{B}$. The probability of eliciting an action potential in SL cells (left) is reduced only for the briefest latency (3 ms), whereas in SP cells (right) action potentials are largely abolished for all latencies. Data from $n=$ $4-5$ cells.

These findings reinforce the functional distinction between these two classes of neuron (Suzuki and Bekkers, 2006, 2011).

\section{Discussion}

Our goal was to identify the microcircuits that are responsible for providing two types of synaptic inhibition-feedforward and feedback - of layer II principal neurons (SL and SP cells) in the anterior piriform cortex of mice. We find that feedforward inhibition, due to GABAergic interneurons in layer Ia, has two variants: $\mathrm{LOT} \rightarrow \mathrm{HZ} \rightarrow \mathrm{SL} / \mathrm{SP}$ and $\mathrm{LOT} \rightarrow \mathrm{NG} \rightarrow \mathrm{SL} / \mathrm{SP}$. Because $\mathrm{HZ}$ cells are only found close to the lateral olfactory tract they provide a more spatially restricted form of feedforward inhibition than that generated by NG cells, which are widely distributed. In contrast to feedforward inhibition, feedback inhibition is generated by interneurons located in deeper layers of the PC. We identify a major type of feedback inhibition that is provided by the following circuit: LOT $\rightarrow \mathrm{SL} \rightarrow \mathrm{fMP} \rightarrow \mathrm{SL} / \mathrm{SP}$. A notable feature of this circuit is the powerful, divergent connections made by fMP cells 
onto the perisomatic regions of numerous SL and SP cells. However, dynamic clamp experiments reveal that SL and SP cells respond in opposite ways to this inhibition, with EPSP time course more sensitive in SL cells and spike output more sensitive in SP cells.

Our results are, of course, subject to the usual proviso that slice experiments are biased toward local circuits that are more likely to be preserved in isolated tissue (Suzuki and Bekkers, 2011). Nevertheless, the feedforward and feedback inhibitory motifs we have identified are likely to be participants in the, as yet, poorly understood network computations that underlie olfactory processing by the PC (Wilson and Bower, 1992; Barnes et al., 2008; Poo and Isaacson, 2009, 2011; Wilson, 2010; Zhan and Luo, 2010; Franks et al., 2011).

\section{Comparison with other work}

Our findings broadly confirm classic work that provided evidence for feedforward and feedback inhibition in the piriform cortex (Satou et al., 1983; Haberly and Bower, 1984; Haberly et al., 1987; Tseng and Haberly, 1988; for review, see Neville and Haberly, 2004). Our results are also consistent with a recent report describing inhibitory microcircuits in the anterior PC (Stokes and Isaacson, 2010). Like us, Stokes and Isaacson (2010) identified feedforward inhibition mediated by interneurons in layer Ia, as well as feedback inhibition provided by fast-spiking interneurons in deeper layers. However, by using our knowledge of the different types of PC interneurons and layer II principal neurons (Suzuki and Bekkers, 2010b, 2011), we have extended their findings in three ways. First, we were able to identify two types of feedforward inhibition. Interestingly, the corresponding inhibition reported by Stokes and Isaacson (2010) appears to be a mixture of our two types. Second, we confirm the involvement of fast-spiking cells in feedback inhibition, but also explicitly address the possible involvement of other neuronal types (regularspiking, bitufted and neurogliaform cells; Figs. 5, 8). Finally, we implicate SL cells, rather than generic pyramidal cells, in generating the excitation that drives feedback inhibition following LOT stimulation (Fig. 6). This is consistent with recent reports that SL cells receive stronger afferent input (Suzuki and Bekkers, 2011; Wiegand et al., 2011). Thus, our data provide more explicit detail about the architecture of these circuits.

Another clear difference between our two studies is that Stokes and Isaacson (2010) focused on the short-term dynamics of inhibition by using trains of LOT stimulation at a range of different strengths. In contrast, we mainly used single, weak shocks to the LOT to elicit minimal synaptic responses and avoid complications due to polysynaptic excitation. However, we did use trains when recording from synaptically connected pairs (Figs. 3, 7, 8). Our pair recordings confirmed the conclusion of Stokes and Isaacson (2010) that feedforward inhibition depresses during trains (Fig. 3B). More puzzling, however, is their finding that feedback inhibition facilitates during trains of LOT stimulation. This was attributed by them to increased excitatory drive of the feedback fast-spiking cells by pyramidal cells, because the latter receive facilitating input from the LOT. However, we report here that fast-spiking cells are (under our weakstimulation conditions) mainly driven by SL cells, not SP cells, and the former do not receive facilitating LOT input (Suzuki and Bekkers, 2006, 2011). A possible explanation for the discrepancy is that, by applying stronger stimulation to recruit feedback inhibition, Stokes and Isaacson (2010) also recruited more SP cells than was the case under our minimal stimulation conditions. It will be important to establish which stimulus strength more closely replicates physiological conditions.

\section{Functional significance}

Feedforward inhibition is a common circuit motif in the neocortex and hippocampus, where it is thought to narrow the temporal window for action potential initiation (Pouille and Scanziani, 2001; Gabernet et al., 2005; Higley and Contreras, 2006). In those brain regions, however, feedforward inhibition is mainly mediated by perisomatic fast-spiking basket cells (Glickfeld et al., 2008; Torborg et al., 2010), unlike our finding in the PC that feedforward inhibition is dendritic. The latter architecture is a consequence of the unusual laminar structure of the PC, whereby afferent inputs are received exclusively on the distal apical dendritic tufts of layer II/III principal cells. It is unclear whether the dendritic feedforward inhibition prominent in the PC serves a similar function to the somatic form seen previously, i.e., whether it synchronizes the timing of action potentials, facilitating coincidence detection (Pouille and Scanziani, 2001). An alternative suggestion is that the depression of feedforward inhibition during a stimulus train acts as a salience filter, allowing principal cells in the PC to respond more vigorously during bursts of input from the olfactory bulb (Stokes and Isaacson, 2010).

Why are there two types of feedforward inhibition, mediated by HZ and NG cells? The somata of HZ cells are close to the LOT and their axons ramify locally, suggesting that principal neurons near the LOT may receive a kind of privileged inhibition from $\mathrm{HZ}$ cells. Because of their faster rise time and weaker depression during trains, inhibitory responses from $\mathrm{HZ}$ cells might enforce greater temporal precision on neurons close to the LOT. In contrast, NG cells are found throughout layer Ia (and in all other layers of the PC; Suzuki and Bekkers, 2010b). As is the case for NG cells in other brain regions, NG cells in the PC provide synaptic inhibition with unusually slow kinetics and strong depression during trains, perhaps involving volume transmission (Oláh et al., 2009; Karayannis et al., 2010; Capogna and Pearce, 2011). Hence, NG cell-mediated feedforward inhibition may be more diffuse than that provided by $\mathrm{HZ}$ cells.

Unlike feedforward inhibition, feedback inhibition in the PC seems to be mainly provided by just one class of interneuron, the soma-targeting fast-spiking multipolar cell. The fMP cell is reminiscent of fast-spiking basket cells found in the hippocampus and neocortex (Freund and Katona, 2007) and, like them, has a profuse axonal arbor that appears to contact the somata of many principal neurons (Yoshimura and Callaway, 2005; Glickfeld et al., 2008; Suzuki and Bekkers, 2010b). This ability of fMP cells to provide powerful perisomatic inhibition of many principal neurons suggests that they may underlie the global inhibition that has been reported in the PC (Poo and Isaacson, 2009; but see also Zhan and Luo, 2010). Importantly, our dynamic clamp experiments also indicate that SL and SP cells respond differently to this feedback inhibition (Figs. 9, 10). In SL cells, feedback inhibition more powerfully shapes the EPSP time course and, hence, temporal summation. This might help to shape synaptic integration in SL cells, assisting them in their suggested role as the primary recipients of afferent information from the olfactory bulb (Suzuki and Bekkers, 2011). In SP cells, in contrast, feedback inhibition more strongly suppresses spike output. This feature might help to prevent runaway excitation building up within the profuse associational connections between SP cells (Franks et al., 2011; Suzuki and Bekkers, 2011; Wiegand et al., 2011).

If $\mathrm{HZ}$, fMP and layer Ia NG cells can be assigned to specific inhibitory microcircuits, what roles can be assigned to the other 
classes of interneurons we have previously identified in the PC (bitufted, regular-spiking and deep NG cells; Suzuki and Bekkers, 2010b)? Under the conditions of our experiments, the BT and rMP cells weakly inhibit layer II principal neurons. However, we have previously reported that both of these cell types receive strongly facilitating associational inputs during trains, whereas fMP cells receive depressing inputs (Suzuki and Bekkers, 2010 b). Hence, BT and rMP cells could operate synergistically with fMP cells, providing inhibition under complementary dynamic conditions.

The work reported here has focused mainly on responses to single stimuli. Future experiments could explore the responses of the different classes of neurons to dynamic or patterned stimulation. Such studies might also allow us to understand the importance of these and other circuits for global oscillations in electrical activity, which are very prominent in the olfactory system (Wilson and Bower, 1992; Neville and Haberly, 2003; Kay et al., 2009; Poo and Isaacson, 2009; Kay and Beshel, 2010).

In conclusion, we have identified the cell types and connections that implement two feedforward circuits and one feedback circuit in the anterior PC. A critical next step will be to examine the in vivo responses of these circuits to physiologically relevant stimuli.

\section{References}

Ascoli GA, Alonso-Nanclares L, Anderson SA, Barrionuevo G, BenavidesPiccione R, Burkhalter A, Buzsáki G, Cauli B, Defelipe J, Fairén A, Feldmeyer D, Fishell G, Fregnac Y, Freund TF, Gardner D, Gardner EP, Goldberg JH, Helmstaedter M, Hestrin S, Karube F, et al. (2008) Petilla terminology: nomenclature of features of GABAergic interneurons of the cerebral cortex. Nat Rev Neurosci 9:557-568.

Barnes DC, Hofacer RD, Zaman AR, Rennaker RL, Wilson DA (2008) Olfactory perceptual stability and discrimination. Nat Neurosci 11:1378-1380.

Bathellier B, Margrie TW, Larkum ME (2009) Properties of piriform cortex pyramidal cell dendrites: implications for olfactory circuit design. J Neurosci 29:12641-12652.

Bekkers JM (2011) Changes in dendritic axial resistance alter synaptic integration in cerebellar Purkinje cells. Biophys J 100:1198-1206.

Bekkers JM, Clements JD (1999) Quantal amplitude and quantal variance of strontium-induced asynchronous EPSCs in rat dentate granule neurons. J Physiol 516:227-248.

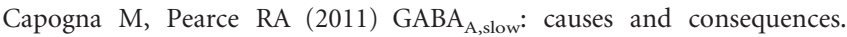
Trends Neurosci 34:101-112.

Davison IG, Ehlers MD (2011) Neural circuit mechanisms for pattern detection and feature combination in olfactory cortex. Neuron 70:82-94.

DeFelipe J (2002) Cortical interneurons: from Cajal to 2001. Prog Brain Res 136:215-238.

Franks KM, Isaacson JS (2005) Synapse-specific downregulation of NMDA receptors by early experience: a critical period for plasticity of sensory input to olfactory cortex. Neuron 47:101-114.

Franks KM, Isaacson JS (2006) Strong single-fiber sensory inputs to olfactory cortex: implications for olfactory coding. Neuron 49:357-363.

Franks KM, Russo MJ, Sosulski DL, Mulligan AA, Siegelbaum SA, Axel R (2011) Recurrent circuitry dynamically shapes the activation of piriform cortex. Neuron 72:49-56.

Freund TF, Katona I (2007) Perisomatic inhibition. Neuron 56:33-42.

Gabernet L, Jadhav SP, Feldman DE, Carandini M, Scanziani M (2005) Somatosensory integration controlled by dynamic thalamocortical feedforward inhibition. Neuron 48:315-327.

Glickfeld LL, Atallah BV, Scanziani M (2008) Complementary modulation of somatic inhibition by opioids and cannabinoids. J Neurosci 28:1824-1832.

Gulledge AT, Stuart GJ (2003) Excitatory actions of GABA in the cortex. Neuron 37:299-309.

Haberly LB, Bower JM (1984) Analysis of association fiber system in piriform cortex with intracellular recording and staining techniques. J Neurophysiol 51:90-112.
Haberly LB, Hansen DJ, Feig SL, Presto S (1987) Distribution and ultrastructure of neurons in opossum piriform cortex displaying immunoreactivity to GABA and GAD and high-affinity tritiated GABA uptake. J Comp Neurol 266:269-290.

Higley MJ, Contreras D (2006) Balanced excitation and inhibition determine spike timing during frequency adaptation. J Neurosci 26:448-457.

Isaacson JS, Scanziani M (2011) How inhibition shapes cortical activity. Neuron 72:231-243.

Johenning FW, Beed PS, Trimbuch T, Bendels MH, Winterer J, Schmitz D (2009) Dendritic compartment and neuronal output mode determine pathway-specific long-term potentiation in the piriform cortex. J Neurosci 29:13649-13661.

Karayannis T, Elfant D, Huerta-Ocampo I, Teki S, Scott RS, Rusakov DA, Jones MV, Capogna M (2010) Slow GABA transient and receptor desensitization shape synaptic responses evoked by hippocampal neurogliaform cells. J Neurosci 30:9898-9909.

Kay LM, Beshel J (2010) A beta oscillation network in the rat olfactory system during a 2-alternative choice odor discrimination task. J Neurophysiol 104:829-839.

Kay LM, Beshel J, Brea J, Martin C, Rojas-Líbano D, Kopell N (2009) Olfactory oscillations: the what, how and what for. Trends Neurosci 32:207-214.

Kerlin AM, Andermann ML, Berezovskii VK, Reid RC (2010) Broadly tuned response properties of diverse inhibitory neuron subtypes in mouse visual cortex. Neuron 67:858-871.

Luna VM, Schoppa NE (2008) GABAergic circuits control input-spike coupling in the piriform cortex. J Neurosci 28:8851-8859.

Manabe H, Kusumoto-Yoshida I, Ota M, Mori K (2011) Olfactory cortex generates synchronized top-down inputs to the olfactory bulb during slow-wave sleep. J Neurosci 31:8123-8133.

Markram H, Toledo-Rodriguez M, Wang Y, Gupta A, Silberberg G, Wu C (2004) Interneurons of the neocortical inhibitory system. Nat Rev Neurosci 5:793-807.

Moore CI, Carlen M, Knoblich U, Cardin JA (2010) Neocortical interneurons: from diversity, strength. Cell 142:189-193.

Neville KR, Haberly LB (2003) Beta and gamma oscillations in the olfactory system of the urethane-anesthetized rat. J Neurophysiol 90:3921-3930.

Neville KR, Haberly LB (2004) Olfactory cortex. In: The synaptic organization of the brain, Ed 5 (Shepherd GM, ed), pp 415-454. New York: Oxford UP.

Oláh S, Füle M, Komlósi G, Varga C, Báldi R, Barzó P, Tamás G (2009) Regulation of cortical microcircuits by unitary GABA-mediated volume transmission. Nature 461:1278-1281.

Poo C, Isaacson JS (2009) Odor representations in olfactory cortex: "sparse" coding, global inhibition, and oscillations. Neuron 62:850-861.

Poo C, Isaacson JS (2011) A major role for intracortical circuits in the strength and tuning of odor-evoked excitation in olfactory cortex. Neuron $72: 41-48$.

Pouille F, Scanziani M (2001) Enforcement of temporal fidelity in pyramidal cells by somatic feed-forward inhibition. Science 293:1159-1163.

Satou M, Mori K, Tazawa Y, Takagi SF (1983) Interneurons mediating fast postsynaptic inhibition in pyriform cortex of the rabbit. J Neurophysiol 50:89-101.

Silver RA (2010) Neuronal arithmetic. Nat Rev Neurosci 11:474-489.

Stettler DD, Axel R (2009) Representations of odor in the piriform cortex. Neuron 63:854-864.

Stokes CC, Isaacson JS (2010) From dendrite to soma: dynamic routing of inhibition by complementary interneuron microcircuits in olfactory cortex. Neuron 67:452-465.

Suzuki N, Bekkers JM (2006) Neural coding by two classes of principal cells in the mouse piriform cortex. J Neurosci 26:11938-11947.

Suzuki N, Bekkers JM (2010a) Inhibitory neurons in the anterior piriform cortex of the mouse: classification using molecular markers. J Comp Neurol 518:1670-1687.

Suzuki N, Bekkers JM (2010b) Distinctive classes of GABAergic interneurons provide layer-specific phasic inhibition in the anterior piriform cortex. Cereb Cortex 20:2971-2984.

Suzuki N, Bekkers JM (2011) Two layers of synaptic processing by principal neurons in piriform cortex. J Neurosci 31:2156-2166.

Tamamaki N, Yanagawa Y, Tomioka R, Miyazaki J, Obata K, Kaneko T (2003) Green fluorescent protein expression and colocalization with cal- 
retinin, parvalbumin, and somatostatin in the GAD67-GFP knock-in mouse. J Comp Neurol 467:60-79.

Torborg CL, Nakashiba T, Tonegawa S, McBain CJ (2010) Control of CA3 output by feedforward inhibition despite developmental changes in the excitation-inhibition balance. J Neurosci 30:15628-15637.

Tseng GF, Haberly LB (1988) Characterization of synaptic mediated fast and slow inhibitory processes in piriform cortex in an in vitro slice preparation. J Neurophysiol 59:1352-1376.

Wiegand HF, Beed P, Bendels MH, Leibold C, Schmitz D, Johenning FW (2011) Complementary sensory and associative microcircuitry in primary olfactory cortex. J Neurosci 31:12149-12158.

Wilson DA (2010) Single-unit activity in piriform cortex during slow-wave state is shaped by recent odor experience. J Neurosci 30:1760-1765.
Wilson DA, Stevenson RJ (2006) Learning to smell: olfactory perception from neurobiology to behavior. Baltimore: The Johns Hopkins UP.

Wilson M, Bower JM (1992) Cortical oscillations and temporal interactions in a computer simulation of piriform cortex. J Neurophysiol 67:981-995.

Yoshimura Y, Callaway EM (2005) Fine-scale specificity of cortical networks depends on inhibitory cell type and connectivity. Nat Neurosci 8:1552-1559.

Zelano C, Mohanty A, Gottfried JA (2011) Olfactory predictive codes and stimulus templates in piriform cortex. Neuron 72:178-187.

Zhan C, Luo M (2010) Diverse patterns of odor representation by neurons in the anterior piriform cortex of awake mice. J Neurosci 30: $16662-16672$. 